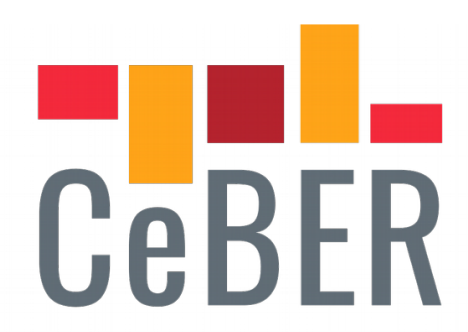

CENTRE FOR BUSINESS AND ECONOMICS RESEARCH

- UNIVERSITY OF COIMBRA

\title{
Asset classification under the IFRS 9 framework for the construction of a banking investment portfolio
}

\author{
Rui Pedro Gonçalves Brito \\ Centre for Business and Economics CeBER and Faculty of Economics, University \\ of Coimbra
}

Pedro Maria Corte Real Alarcão Judice

ISCTE Business Research Unit

CeBER Working Papers

No. 6 / 2020 


\title{
Asset classification under the IFRS 9 framework for the construction of a banking investment portfolio
}

\author{
R. P. Brito* $\quad$ P. Júdice ${ }^{\dagger}$
}

\begin{abstract}
In this paper we perform a quantitative analysis, under the IFRS 9 framework, on the tradeoff of classifying a financial asset at amortized cost versus at fair value. We define and implement a banking impairment model in order to quantify the forward-looking expected credit loss. Based on the suggested impairment model we conduct a backtest on the 10-year Portuguese Government bonds, for the time period from January 2003 to December 2019. The Portuguese bonds' history constitutes a very rich data set for our experiment, as these bonds have experienced significant downgrades during the 2011-2014 financial crisis. We suggest a quantitative and systematic approach in order to find efficient allocations, in an income/downside comprehensive income bi-dimensional space. Resorting to stochastic simulation, we show a possible approach to mitigate the estimation error ingrained in the proposed bi-objective stochastic model. Finally, we assess the out-of-sample performance of some of the suggested efficient allocations.
\end{abstract}

JEL Classification: C44; C51; C61; C63; C88; G11; G24

Keywords: Asset Classification, Backtesting, IFRS 9, Derivative-Free Optimization, Sensitivity Analysis, Stochastic Simulation

*CeBER, University of Coimbra, 3004-512 Coimbra, Portugal (rbrito@uc.pt). Support for this author was provided by FCT under the Stimulus of Scientific Employment - Individual Support 2017, CEECIND/01010/2017.

${ }^{\dagger}$ Montepio Geral, 1200-094 Lisbon, Portugal (pajudice@montepio.pt) and ISCTE Business Research Unit, 1649-026 Lisbon, Portugal. This research is independent from the activity at Montepio and does not reflect any views of this institution. 


\section{Introduction}

In the portfolio optimization literature it is possible to find several studies on backtesting and on the out-of-sample performance analysis of portfolios constructed under frameworks inspired by the seminal work of Markowitz (1952). When in face of a portfolio optimization model it is well known that special attention should be given to the inputs' estimation errors (see, e.g., Chopra and Ziemba 1993). Despite the sophisticated models that have arisen, over the years, the truth is that simple heuristics often are able to achieve superior out-of-sample performances (see, e.g., DeMiguel et al. 2009). This happens because a portfolio optimization model can be seen as a two step model (Michaud, 1989): in one step the model's inputs need to be estimated (with error); in the second step the optimization is performed (the estimation error is optimized!). In turn, a heuristic, free of estimation error, leads to superior out-of-sample results (notwithstanding that in-sample it is a suboptimal strategy). This does not mean that all the portfolio optimization models do not work in practice; it tell us that when building such portfolio optimization models somehow the estimation error sensitiveness must be addressed. As Gigerenzer (2015) states, in situations of risk (where we can generate future scenarios with a certain probability) optimization models can work just fine, and in situations of uncertainty (where we can not anticipate anything about the future) heuristics, that incorporate the intuition developed over the years, tend to produce better results.

Regarding optimization models for the bank balance sheet, the literature is more sparse than for the case of portfolio optimization, but still substantial. It had its beginning at least since the sixties with the paper of Kalman and Hammer (1967). In the eighties we highlight the papers of Koehn and Santomero (1980) and Kusy and Ziemba (1986). More recently we have, for example, the works of Diamond and Rajan (2000), Halaj (2013) and Schmaltz et al. (2014). Both the works of Halaj (2013) and Schmaltz et al. (2014) already address the impact of recent regulatory constraints imposed by Basel III. Nevertheless, at the present date there is no record of any study that deals with the more recent accounting rules. Besides that, these studies propose optimization models for the bank balance sheet but overlook the estimation error and the out-of-sample performance.

Accounting rules are one of the key variables in the optimization of a bank balance sheet. Motivated by the 2008 financial crisis, the International Accounting Standards Board (IASB) issued the International Financial Reporting Standard 9 (IFRS 9), on July 24, 2014, and replaced the International Accounting Standard 39 (IAS 39). IFRS 9 has become mandatory on January 1, 2018. Therefore, in 2018 banks had to adapt to the new accounting rules. One of the practical pressing aspects issued by IFRS 9 lies on financial asset classification. The main purpose of this paper is to analyze the way a bank investment manager can determine, quantitatively, how a given investment should be allocated between amortized cost versus fair value. Thereby, instead of looking to the optimization of the whole bank balance sheet, we concentrate our attention to the investment side.

Motivated by the fact that banks tend to invest in sovereign debt (Gennaioli et al., 2018), we begin by designing a backtest on the 10-year Portuguese Government bonds 
for the time period between 2003 and 2019. Due to the experienced downgrades during the 2011-2014 financial crisis, the history of the Portuguese bonds constitutes a very rich data set. As IFRS 9 leaves the approach to the impairment model open to banks, we implement one of the possibilities in order to compute the expected credit loss. The idea is to be able to assess the annual income and the annual comprehensive income of different allocations to amortized cost and to fair value. From the backtest's results, we stress that the higher the allocation of the investment to fair value, the higher the annual income achieved and the greater the variability of the annual comprehensive income. The results depend on two important determinants: the time horizon defined by the bank investment manager and the threshold from which she/he decides to realize gains at fair value.

According to the best of our knowledge, in the literature there is no backtest on the classification of financial assets at amortized cost versus fair value. Furthermore, no quantitative model, that gives some insight about this decision, is known. In order to give a more substantial contribution to the literature, we construct an optimization model that allows the bank investment manager to directly find efficient allocations (amortized cost versus fair value) in a risk-return bi-dimensional space. As a return measure we define the average annual income and as a risk measure we use a downside risk measure (the semivariance of the annual comprehensive income, which has a direct impact on the bank's own funds and regulatory capital ratios). Given the non-smoothness of the proposed bi-objective model, in order to find the efficient allocations we use a derivativefree algorithm. We discuss and implement a possible approach to mitigate the estimation error, present in the model. This approach is based on stochastic simulation and scenario generation. Finally, based on simulated paths (for a 10-year period), we assess the out-ofsample performance of efficient allocations, selected according the proposed bi-objective model. The results suggest a robust performance of the efficient allocations, in both the considered objectives, including when compared to other benchmark allocations (namely, the hard to beat equally weighted heuristic that corresponds to allocating the investment equally to amortized cost and to fair value).

The remainder of this paper proceeds as follows. In Section 2 we make a brief presentation on the IFRS 9 rules around the classification of financial assets. In Section 3 we perform all the quantitative analysis: we begin by defining the impairment model, needed to compute the expected credit loss; then, we implement a backtest on the 10-year Portuguese Government bonds and analyze the respective results; the suggested bi-objective model is motivated, presented and discussed; and finally, we develop the stochastic simulation (scenario generation) and the out-of-sample performance assessment. In the last section, Section 4, we present the main conclusions of the paper and discuss some possible directions for future work.

\section{The IFRS 9 Framework}

The classification system of IFRS 9 (IFRS Foundation ${ }^{\circledR}$, 2017) is based on the business model in which assets are managed and their cash flow characteristics (KPMG, 2016). 
Under the IFRS 9 framework, financial assets are classified into one of the three categories: amortized cost (AC), fair value through other comprehensive income (FVOCI) and fair value through profit or loss (FVPL). The categories of held to maturity, loans and receivables and available for sale, existing in the IAS 39 framework are eliminated (KPMG, 2016).

A financial asset is classified at AC if the financial asset is held to collect contractual cash flows and if the financial asset give rise to cash flows that are solely payments of principal and interest on the principal amount outstanding. As examples of financial assets that can be classified at amortized cost we have trade receivables, loan receivables, investments in government bonds that are not held for trading and investments in term deposits at standard interest rates. In turn, a financial asset is classified at FVOCI if it is held to collect and sell and the financial asset give rise on specified dates to cash flows that are solely payments of principal and interest on the principal amount outstanding. As examples we have investments in government or corporate bonds where the investment period is shorter than maturity. If a financial asset does not fall into any of the two previous classifications, then it is classified as FVPL. As examples we have held for trading financial assets.

In this paper we focus on the tradeoff between a financial asset being classified at $\mathrm{AC}$ or at FVOCI (hereafter FV), from the perspective of a banking portfolio construction. If a financial asset is classified at FV it will allow to realize potencial gains that may occur since the acquisition date to maturity, whereas if it is classified at AC this will not be possible. However, a financial asset classified at FV will expose the bank capital to market fluctuations. Therefore, according to the type of financial asset to include in the banking investment portfolio, the bank investment manager should carefully consider what business model to adopt.

Credit risk can be explained as the risk of default on a debt due to a borrower that has not fulfilled its obligations. According to the IFRS 9 framework, the financial assets classified as AC or FV are impaired under a single impairment model (Volarević and Varović, 2018). IFRS 9 replaces the incurred loss model, used under the IAS 39, with a forward-looking expected credit loss (ECL). In the IAS 39 framework, value adjustments resulted from objective facts; in turn, the IFRS 9 impairment model focuses on possible future losses and therefore makes use of a greater amount of information (e.g., macroeconomic data). According to the "general approach" (see BDO 2017, for further details) the ECL impairment model consists of three stages based on changes in credit quality: stage 1 , stage 2 and stage 3 .

Following BDO (2017), stage 1 ("Performing"), corresponds to the case where there is no indication of decline in credit quality since acquisition; for financial assets in this stage the 12-month ECL must be recognized and the interest income is recognized on a gross basis (interest will be calculated on the gross carrying amount of the financial asset before adjusting for ECL). Stage 2 ("underperforming"), corresponds to the case where there is a significant increase in credit risk (SICR) since acquisition; when a financial asset is transferred to this stage, lifetime ECL must be recognized; nevertheless, the interest income is still recognized on a gross basis. Finally, Stage 3 ("non-performing"), 
corresponds to the case where the financial asset is credit impaired; the lifetime ECL continues to be recognized but the interest income is now recognized on a net basis (interest income will be calculated based on the gross carrying amount of the financial asset less the ECL).

\section{Quantitative Analysis}

With the aim of helping the bank investment manager in the design of a quantitative strategy for asset classification, in this section we perform a quantitative analysis of the tradeoff between a financial asset being classified at AC or at FV.

We begin by setting up a backtest on the 10-year Portuguese Government bonds for the time period between 2003 and 2019 . We have gathered monthly data for the yields ${ }^{1}$. As funding rates we have collected monthly data for the interest rate in term deposits (deposits with agreed maturity, up to 1 year) of individuals ${ }^{2}$ (resident individuals in the monetary union and Portuguese emigrants outside the monetary union). Moreover, for the sample time period, we have also gathered data of the Portuguese Government bonds credit ratings according to the Moody's Agency ${ }^{3}$. All these historical data are reported in Figure 1.

Figure 1: Historical Data Gathered

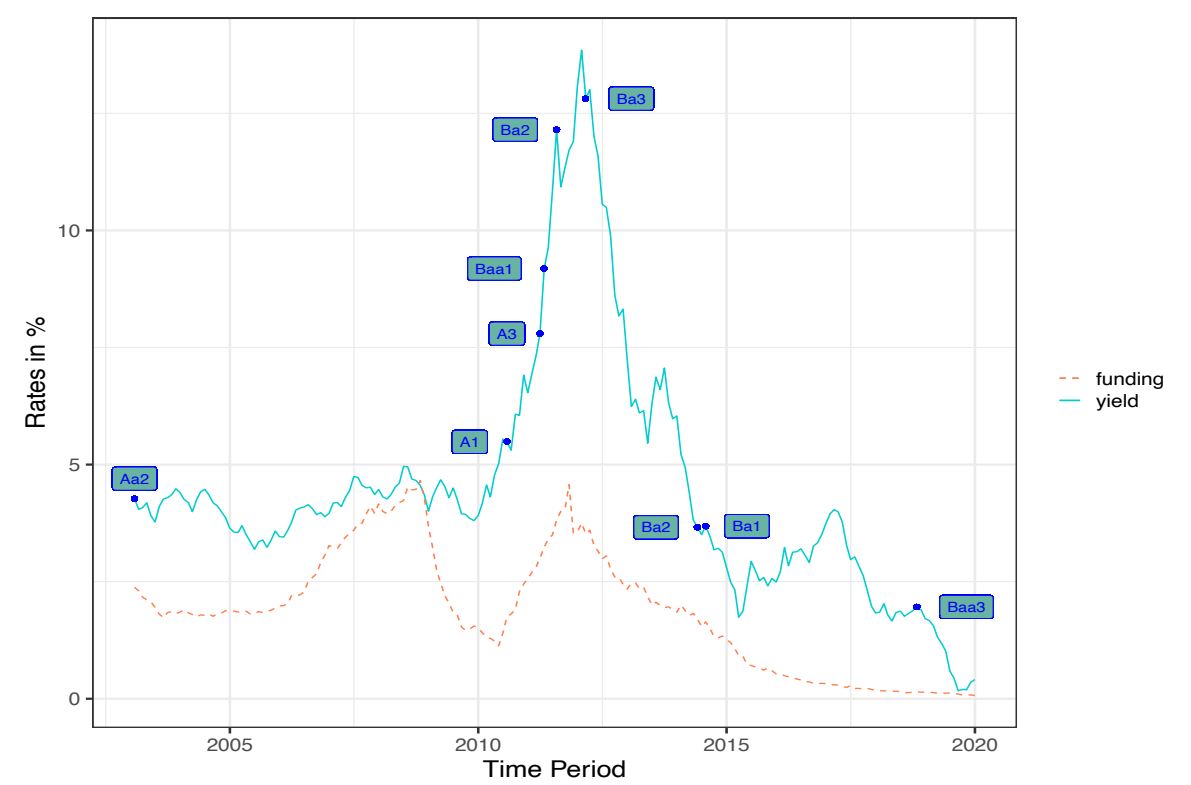

This figure reports the monthly funding rates (interest rate on term deposits of individuals in Portugal), the monthly yields of the 10-year Portuguese Government bonds and the corresponding ratings changes (according to the Moody's Agency notation) within the time period 2003-2019.

\footnotetext{
${ }^{1}$ This data is publicly available on https://bpstat.bportugal.pt/. We have collected all the available data in which the first observation corresponds to January 2003.

${ }^{2}$ Monthly data, for the funding rates, is publicly available on https://bpstat.bportugal.pt.

${ }^{3}$ This data is publicly available on https://pt.countryeconomy.com/governo/ratings/portugal.
} 
We are interested in analyzing the impact of annual decisions (namely, looking to the annual income and the annual comprehensive income); thus, we have annualized all the collected data. Thereby, the annual yields and the annual funding rates correspond to an annual average. Regarding the rating, according to the Moody's Agency notation we have sixteen (considering modifiers) different rating levels: B3, B2, B1 $\mapsto$ highly speculative grade; Ba3, Ba2, Ba1 $\mapsto$ non-investment (speculative) grade; Baa3, Baa2, Baa1 $\mapsto$ medium-low grade; A3, A2, A1 $\mapsto$ medium-high grade; Aa3, Aa2, Aa1 $\mapsto$ high grade; Aaa $\mapsto$ prime. By assigning a numerical value to each possible rating level (1 to 16), this allows us to compute the annual average (rounded value) rating for the sample under analysis ${ }^{4}$. The three annualized series (yields, funding rates and rating levels) are reported in Figure 2.

Even though our analysis could be applied to any other financial assets, we decided to focus on the 10-year Portuguese Government bonds. The evolution of the 10-year Portuguese Government bonds has been exhibiting very unique dynamics as we can see in Figure 1. In particular, the data set shows a substantial amount of downgrades which allows us to assess the impacts of transitioning assets from Stage 1 to Stages 2 and 3. Moreover, banks make substantial investments in sovereign debt (Gennaioli et al., 2018), given the low capital requirements and high liquidity. Thereby, we have chosen to carry out the analysis on the 10-year Portuguese Government bonds, which in itself presents several challenges (due to its specific dynamics) and, according to our best knowledge, corresponds to the first time that such an analysis is made.

\subsection{Impairment Model Definition}

One of the great "freedoms" given to the banks by IFRS 9, in the implementation of the impairment model, is related to the computation of the ECL. Since IFRS 9 does not stipulate how to compute the $E C L$ it is not straightforward to implement it. Banks are expected to develop their internal models making use of past and future information.

In order to quantify the bond credit risk, we begin by defining the lifetime $E C L$ as

$$
E C L^{(\text {lifetime })}=\sum_{t=1}^{T} E C L_{t},
$$

where $E C L_{t}$ represents the expected credit loss at time $t$ and $T$ is the bond maturity. Following KPMG (2017), $E C L_{t}$ depends on four factors: (1) the discount factor; (2) the survival probability up to time $t$; (3) the probability of default between time $t$ and time $t+1 ;(4)$ the loss given default $(L G D)$. Thereby we can model the lifetime $E C L$ as

$$
E C L^{(\text {lifetime })}=\sum_{t=1}^{T} \exp (-r t) \times \exp (\lambda t) \times \lambda \times L G D,
$$

\footnotetext{
${ }^{4}$ In the monthly data collected we observe eight different rating levels (see Figure 1): Ba3, Ba2, Ba1, Baa3, Baa1, A3, A1 and Aa2.
} 
Figure 2: Annualized Data

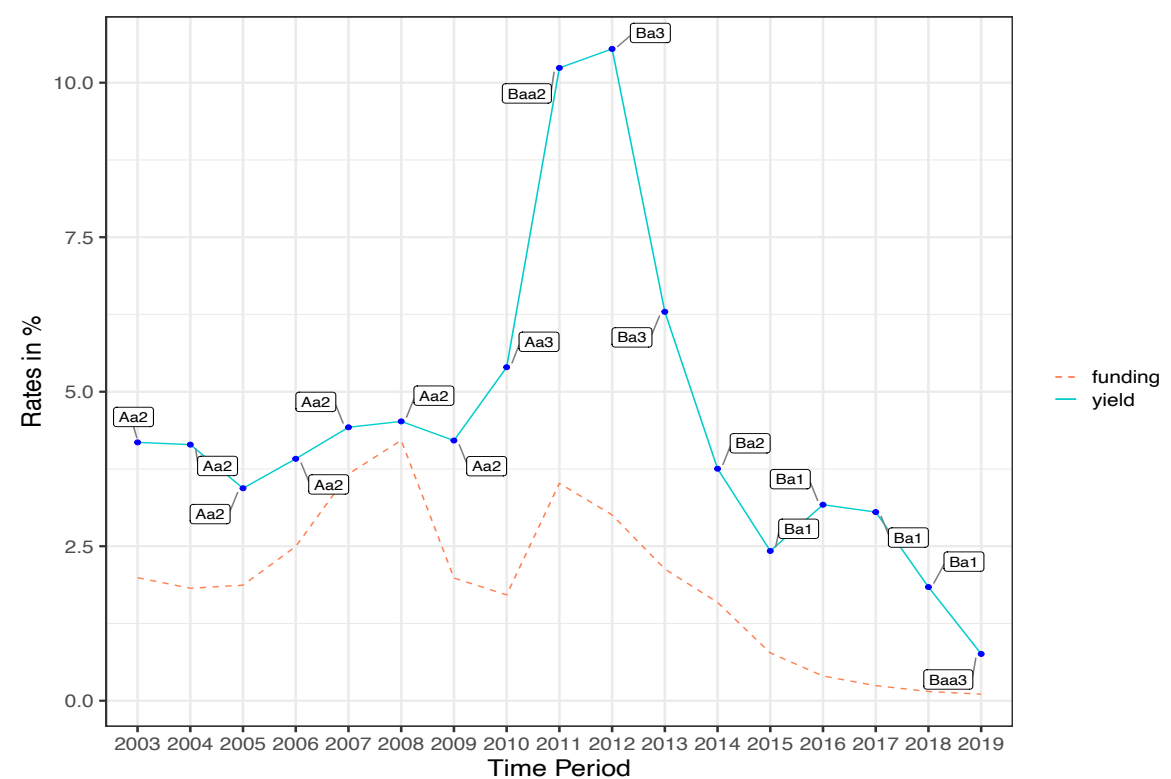

This figure reports the annual average funding rates (interest rate on term deposits of individuals in Portugal), the annual average yields of the 10-year Portuguese Government bonds and the corresponding annual average rating levels (according to the Moody's Agency notation) within the time period 2003-2019.

where $r$ represents the discount rate and $\lambda$ defines the intensity of the Poisson process that represents the marginal probability of default. Equation (2) can be approximated by the following integral

$$
L G D \int_{0}^{T} \lambda \exp (-(r+\lambda) t) d t=L G D \times \frac{\lambda}{\lambda+r} \times[1-\exp [-(\lambda+r) T]] .
$$

We can observe from Equation (3), that the loss increases with $L G D$ and maturity. Moreover, it has an asymptote in $\lambda /(\lambda+r)$, i.e., $\lambda /(\lambda+r)$ is an upper bound to the loss.

Regarding the stage allocation, IFRS 9 does not define what an SICR is, which determines if an asset should change from stage 1 to stage 2 . A bank must identify the factors that indicate an SICR based on the specific nature of the financial asset (PWC, 2017). Commonly there are three elements taken into account in this identification (see, PWC 2017, for further details): a quantitative element, a qualitative element and the 30 days past due backstop indicator in IFRS 9 paragraph 5.5.11 (IFRS Foundation ${ }^{\circledR}, 2017$ ). Since great "freedom" is given to banks in defining what constitutes an SICR, several banks are undecided about which indicators to use (Ernst \& Young, 2017). However, a great number of banks have declared to make use of the low credit risk simplification as their main indicator for debt securities (Ernst \& Young, 2017). In the context of the IFRS 9 framework, a financial asset can be classified as having low credit risk if it has a rating of "investment grade" or above (BDO, 2018). According to IFRS 9 paragraph 5.5.10 (IFRS Foundation ${ }^{\circledR}$, 2017), if a financial asset is classified at a reporting date as having low credit risk, then it is assumed that an SICR has not occurred since initial recognition. 
This can be seen as an absolute threshold (PWC, 2017).

In our analysis, we assume the following criteria: stage 1 - investment grade financial assets or financial assets that have not had a downgrade greater or equal than 3 notches since origination; Stage 2 - speculative grade financial assets or financial assets that have had a downgrade of at least 3 notches since origination.

\subsection{Backtest}

According to the methodology proposed in the previous section, to compute the $E C L$, three inputs are needed: the intensity of the Poisson process $(\lambda)$, the discount rate $(r)$, and the $L G D$.

The intensity of the Poisson process can be calibrated using probabilities of default. Nevertheless, we highlight that probabilities of default inferred from market instruments, such as credit default swaps, must not be used in the computation of the ECL. Just as insurers do not use insurance premiums to infer probabilities associated with events (e.g. mortality tables), credit default swaps should not be used to infer probabilities of default, given the uncertainties relating to market risk premia, counterparty risks and market frictions (for further details see, e.g., Jarrow 2012). Thus, to calibrate the Poisson process intensity, historical data should be used. In this paper we use the sovereign issuerweighted cumulative default rates, made public by Moody's Investors Service (2019). For general purposes, we consider, without modifiers, six different rating levels (in ascending order: B, Ba, Baa, A, Aa, Aaa $)^{5}$. Therefore, each sovereign issuer-weighted cumulative default rate can be seen as a $p_{k, n}$ element, with $k=1, \ldots, 6 ; n=1, \ldots, 10$ (where $k$ represents each rating level and $n$ the number of years considered in Moody's Investors Service 2019). We have calibrated each intensity $\lambda^{(k)}$ (with $k=1, \ldots, 6$ ) through the minimum squares method. Accordingly, each intensity, $\lambda^{(k)}$, corresponds to the solution of the following optimization problem

$$
\min _{\lambda^{(k)} \in \mathcal{R}} \sum_{k=1}^{K} \sum_{n=1}^{N}\left[1-\exp \left(\lambda^{(k)} \times n\right)-p_{k, n}\right]^{2},
$$

where $K=6, N=10$, and $1-\exp \left(\lambda^{(k)} \times n\right)$ represents the model's $n$-year probability of default. Problem (4) has a nonlinear but smooth objective function; thereby it can be solved straightforwardly by a nonlinear optimization algorithm. We have used the Broyden-Fletcher-Goldfarb-Shanno algorithm (this algorithm was originally and simultaneously published by Broyden 1970, Fletcher 1970, Goldfarb 1970 and Shanno 1970), also known as the BFGS algorithm. The results are reported in Table 1.

Moody's Investors Service (2019) also reports the historical average value-weighted sovereign recovery rate $(R R), R R=0.41$. Thereby the corresponding historical average $L G D$ is equal to $0.59(L G D=R R-1)$. We use this historical value for the computation of the $E C L$.

\footnotetext{
${ }^{5} \mathrm{~B}$ - highly speculative grade; $\mathrm{Ba}$ - non-investment (speculative) grade ; Baa - medium-low grade ; A - medium-high grade ; Aa - high grade; Aaa - prime.
} 
Table 1: Calibrated Intensities

\begin{tabular}{lr}
\hline Rating Level & \multicolumn{1}{c}{ Intensity } \\
\hline Aaa & $0.000390 \%$ \\
Aa & $0.112 \%$ \\
A & $0.349 \%$ \\
Baa & $0.273 \%$ \\
Ba & $1.106 \%$ \\
B & $2.477 \%$ \\
\hline
\end{tabular}

This table reports the Poisson process intensities (see Equation (3)) for each rating level. These intensities correspond to the solution of Problem (4), using as input parameters the sovereign issuer-weighted cumulative default rates (Moody's Investors Service, 2019).

As discount rate, $r$ (see Equation (3)), we use the 12-month Euribor rate ${ }^{6}$ for the period under analysis, 2003-2019.

Once defined the three inputs needed to implement the methodology described in Section 3.1, the lifetime $E C L$ in year $i$ of a bond acquired in year $j, E C L_{i, j}^{\text {(lifetime) }}$, is given by

$$
\begin{aligned}
E C L_{i, j}^{(\text {lifetime })}= & L G D \times\left(\frac{\lambda_{i}^{(k)}}{\lambda_{i}^{(k)}+r_{i}}\right) \times\left[1-\exp \left[-\left(\lambda_{i}^{(k)}+r_{i}\right)[10-(i-j)]\right]\right] \\
& \forall i \in I=\{(j+1), \ldots,(j+10)\} ; j \in J=\{1, \ldots, s\},
\end{aligned}
$$

where $s$ is the number of sample periods (for the data under analysis is equal to 17, corresponding to the number of years for the time period 2003-2019), $r_{i}$ is the discount rate for year $i$, and $\lambda_{i}^{(k)}$ represents the intensity of the Poisson process (see Table 1) associated to the rating level $k(1,2,3,4,5$ or 6$)$ observed in year $i$.

In turn, the one-year (12-month) $E C L$ in year $i$ of a bond acquired in year $j, E C L_{i, j}^{\text {(one-year) }}$, can be computed by

$$
\begin{aligned}
E C L_{i, j}^{(\text {one-year })}= & L G D \times\left(\frac{\lambda_{i}^{(k)}}{\lambda_{i}^{(k)}+r_{i}}\right) \times\left[1-\exp \left[-\left(\lambda_{i}^{(k)}+r_{i}\right)\right]\right] \\
& \forall i \in I=\{(j+1), \ldots,(j+10)\} ; j \in J=\{1, \ldots, s\} .
\end{aligned}
$$

We know that the price of a bond depends on the coupon rate $c$, yield $y$ and time to maturity $T$. Therefore, the bond price, $P(c, y, T)$, can be computed as

$$
P(c, y, T)=\sum_{t=1}^{T} \frac{c}{(1+y)^{t}}+\frac{1}{(1+y)^{T}} .
$$

\footnotetext{
${ }^{6}$ This data is publicly available on https://www.euribor-rates.eu/.
} 
Given the sum of the first $n$ terms of a geometric progression, Equation (7) can be expressed as

$$
\begin{aligned}
P(c, y, T) & =c \sum_{t=1}^{T} \frac{1}{(1+y)^{t}}+\frac{1}{(1+y)^{T}} \\
& =c\left(\frac{1}{1+y}\right)\left[\frac{1-\left(\frac{1}{1+y}\right)^{T}}{1-(1+y)}\right]+\frac{1}{(1+y)^{T}} \\
& =\frac{c}{y}\left[1-\frac{1}{(1+y)^{T}}\right]+\frac{1}{(1+y)^{T}} \\
& =\frac{c}{y}-\frac{c}{y} \frac{1}{(1+y)^{T}}+\frac{1}{(1+y)^{T}} \\
& =\frac{c}{y}+\frac{1}{(1+y)^{T}}\left(1-\frac{c}{y}\right)
\end{aligned}
$$

Following the accounting dynamics (double-entry bookkeeping, T-accounts) that a bank investment portfolio must obey (see, e.g., Horngren et al. 1998; Weygandt et al. 2012, for further details), at AC, we measure the originated income (diference between the margin impact and the impairment flow), in year $i$ by the bonds' investment made in year $j, x_{i, j}^{(a c)}$, as

$$
\begin{aligned}
x_{i, j}^{(A C)}= & M I_{i, j}^{(A C)}-I F_{i, j}^{(A C)}=\left(y_{j}-f_{i}\right) \times w^{(A C)}-\left(I S_{i, j}^{(A C)}-I S_{i-1, j}^{(A C)}\right) \\
& \forall i \in I=\{(j+1), \ldots,(j+10)\} ; j \in J=\{1, \ldots, s-1\},
\end{aligned}
$$

where $y_{j}$ represents the 10-year Portuguese Government bond yield in year $i, f_{i}$ is the funding rate in year $i, w^{(A C)}$ is the proportion of the bonds' investment allocated to $\mathrm{AC}$ and $I S_{i, j}^{(A C)}$ is the impairment's stock in year $i$, of the proportion of the bonds' investment (in year $j$ ) allocated to AC. In case of the existence of an SICR (see Section 3.1), I $S_{i, j}^{(A C)}$, is computed as

$$
\begin{aligned}
I S_{i, j}^{(A C)}= & E C L_{i, j}^{(\text {lifetime })} \times w^{(A C)} \\
& \forall i \in I=\{(j+1), \ldots,(j+10)\} ; j \in J=\{1, \ldots, s-1\} .
\end{aligned}
$$

If an SICR did not occur, then $I S_{i, j}^{(A C)}$, is computed as

$$
I S_{i, j}^{(A C)}=E C L_{i, j}^{(\text {one-year })} \times w^{(A C)} .
$$

In turn, at FV, we measure the originated income (diference between the margin impact and the impairment flow plus the gains if realized), in year $i$ by the bonds' investment made in year $j, x_{i, j}^{(F V)}$, as 


$$
\begin{aligned}
x_{i, j}^{(F V)}= & M I_{i, j}^{(F V)}-I F_{i, j}^{(F V)}+\mathbb{1}_{A}(x) *\left[P\left(y_{j}, y_{i},(j+10)-i\right)-1\right] * w^{(F V)} \\
= & \left(y_{j}-f_{i}\right) \times w^{(F V)}-\left(I S_{i, j}^{(F V)}-I S_{i-1, j}^{(F V)}\right) \\
+ & \mathbb{1}_{A}(x) *\left[P\left(y_{j}, y_{i},(j+10)-i\right)-1\right] * w^{(F V)} \\
& \forall i \in I=\{(j+1), \ldots,(j+10)\} ; j \in J=\{1, \ldots, s-1\}
\end{aligned}
$$

where $P(\cdot, \cdot, \cdot)$ is defined in Equation $(7), I S_{i, j}^{(F V)}$ is the impairment's stock in year $i$, of the proportion of the bonds' investment (in year $j$ ) allocated to FV (it is computed in an analogous way as described in Equation (10) and Equation (11)), $w^{(F V)}$ is the proportion of the bonds' investment allocated to $\mathrm{FV}$, and $\mathbb{1}(\cdot)$ represents the indicator function, $A=\left\{y_{j}-y_{i}>=\tau\right\}$. $\tau$ defines a threshold from which the bank investment manager decides to realize the gains or not. A careful choice of this decision variable is determinant in deciding what proportion of the investment should be allocated to FV. Note that the decision to realize gains, in a given time period, may lead to a sacrifice of future gains through the margin impact.

The comprehensive income, at AC, in year $i$ by the bonds' investment made in year $j, z_{i, j}^{(A C)}$, is equal to the income, $x_{i, j}^{(A C)}$. At FV, the comprehensive income (income plus other comprehensive income), in year $i$ by the bonds' investment made in year $j, z_{i, j}^{(F V)}$, is computed as

$$
\begin{aligned}
z_{i, j}^{(F V)}= & I_{i, j}^{(F V)}+O C I_{i, j}^{(F V)}=M I_{i, j}^{(F V)}+M V_{i, j}^{(F V)} \\
= & \left(y_{j}-y_{i}\right) \times w^{(F V)}+ \\
+ & {\left[P\left(y_{j}, y_{i},(j+10)-i\right)-1\right] * w^{(F V)} } \\
- & {\left[P\left(y_{j}, y_{i-1},(j+10)-(i-1)\right)-1\right] * w^{(F V)} } \\
& \forall i \in I=\{(j+1), \ldots,(j+10)\} ; j \in J=\{1, \ldots, s-1\}
\end{aligned}
$$

where $O C I_{i, j}^{(F V)}$ and $M V_{i, j}^{(F V)}$ represent, respectively, the other comprehensive income and the market fluctuations, in year $i$ by the bonds' investment made in year $j$.

In what follows we consider that the bank investment manager invests a fixed amount, $M$, each year ${ }^{7}$ on the 10 -year Portuguese Government bonds. Since the annual income and the annual comprehensive income are the result of different invested amounts (for example, the income in 2005 results from the investments made in 2003 and 2004; in turn, the income of 2006 results from the investments made in 2003, 2004 and 2005; and so on), the results will be presented in percentage of the annual fixed amount invested $(M)$. The bank investment manager faces, each year, the tradeoff between what proportion of the investment must be allocated to $\mathrm{AC}$ and what proportion must be allocated to $\mathrm{FV}$. The proportion of the investment allocated to AC must obey the rule that a bond acquired in year $j$ will be in the bank investment portfolio until maturity, i.e., until the year $j+10$. In turn, the proportion of the investment allocated to FV should follow the rule that a bond acquired in year $j$ will be sold in year $i$ with $j \leq i \leq j+9$ if $y_{j}-y_{i} \geq \tau$, otherwise

\footnotetext{
${ }^{7}$ In practice, each investment decision is made in the end of the corresponding year, the first one made in the end of 2003 and the last one made in the end of 2018.
} 
it will be in the bank investment portfolio until maturity, i.e., the year $j+10$. We begin by realistically assuming that $\tau=0.05$ (500 basis points). All the gains are reinvested in the next period at $\mathrm{FV}$. We consider four different settings:

- Setting \#1 - the case where the bank investment manager allocates the investment totally to $\mathrm{AC}\left(w^{(A C)}=1\right.$ in Equation $\left.(9)\right)$ or to $\mathrm{FV}\left(w^{(F V)}=1\right.$ in Equation (12) and Equation (13));

- Setting \#2 - the case where the bank investment manager allocates $50 \%$ of the investment to $\mathrm{AC}\left(w^{(A C)}=0.5\right.$ in Equation $\left.(9)\right)$ and $50 \%$ to $\mathrm{FV}\left(w^{(F V)}=0.5\right.$ in Equation (12) and Equation (13));

- Setting \#3 - the case where the bank investment manager allocates $25 \%$ of the investment to $\mathrm{AC}\left(w^{(A C)}=0.25\right.$ in Equation $\left.(9)\right)$ and $75 \%$ to $\mathrm{FV}\left(w^{(F V)}=0.75\right.$ in Equation (12) and Equation (13));

- Setting \#4 - the case where the bank investment manager allocates $75 \%$ of the investment to $\mathrm{AC}\left(w^{(A C)}=0.75\right.$ in Equation $\left.(9)\right)$ and $25 \%$ to $\mathrm{FV}\left(w^{(F V)}=0.25\right.$ in Equation (12) and Equation (13)).

In Figure 3 and Figure 4 we report, respectively, the annual income and the annual comprehensive income, for each of the four considered settings. There is one year that stands out immediately in all these figures, the 2011 year. In May 2011, the Portuguese Government signed the $€ 78$ billion bailout program (European Comission, 2011) with the European Commission (Eurogroup), the European Central Bank and the International Monetary Fund. In this year the 10-year Portuguese Government bonds' yield climbed to $10.24 \%$ (see Figure 2) and as the result we observe a considerable drop in the income (see Figure 3) and comprehensive income (see Figure 4). In setting \#1, regardless of the allocation type (AC or FV), there is a drop of $0.16 \%$ of $M$ ( €0.16 for each $€ 100$ of the fixed amount, $M$, invested each year from 2003 until 2011) in the income and a drop of exactly the same magnitude in the comprehensive income if the allocation is done at AC; if the allocation is done at FV a huge drop, equal to $134.14 \%$ of $M$ (€134.14 for each $€ 100$ of the fixed amount, $M$, invested each year from 2003 until 2011), is observed in the comprehensive income. In settings $\# 2, \# 3$ and \#4 the drop in the income is the same observed in setting \#1 but has different origins: in setting \#2 a drop of $0.08 \%$ of $M$ results from the allocation to $\mathrm{AC}$ and the other $0.08 \%$ of $M$ from the allocation to $\mathrm{FV}$; in setting \#3 we observe a drop of $0.04 \%$ of $M$ from the allocation to AC and a drop of $0.12 \%$ of $M$ from the allocation to $\mathrm{FV}$; in setting \#4 a drop of $0.12 \%$ of $M$ results from the allocation to $\mathrm{AC}$ and a drop of $0.04 \%$ of $M$ results from the allocation to $\mathrm{FV}$. Regarding the comprehensive income: in setting \#2 it drops $67.15 \%$ of $M(0.08 \%$ of $M$ from the allocation to $\mathrm{AC}$ and $67.07 \%$ of $M$ from the allocation to $\mathrm{FV}$ ); in setting \#3 it drops $100.65 \%$ of $M(0.04 \%$ of $M$ from the allocation to AC and $100.61 \%$ of $M$ from the allocation to FV); finally, in setting \#4, the comprehensive income drops $33.66 \%$ of $M$ ( $0.12 \%$ of $M$ from the allocation to $\mathrm{AC}$ and $33.54 \%$ of $M$ from the allocation to FV). It 
Figure 3: Annual Income
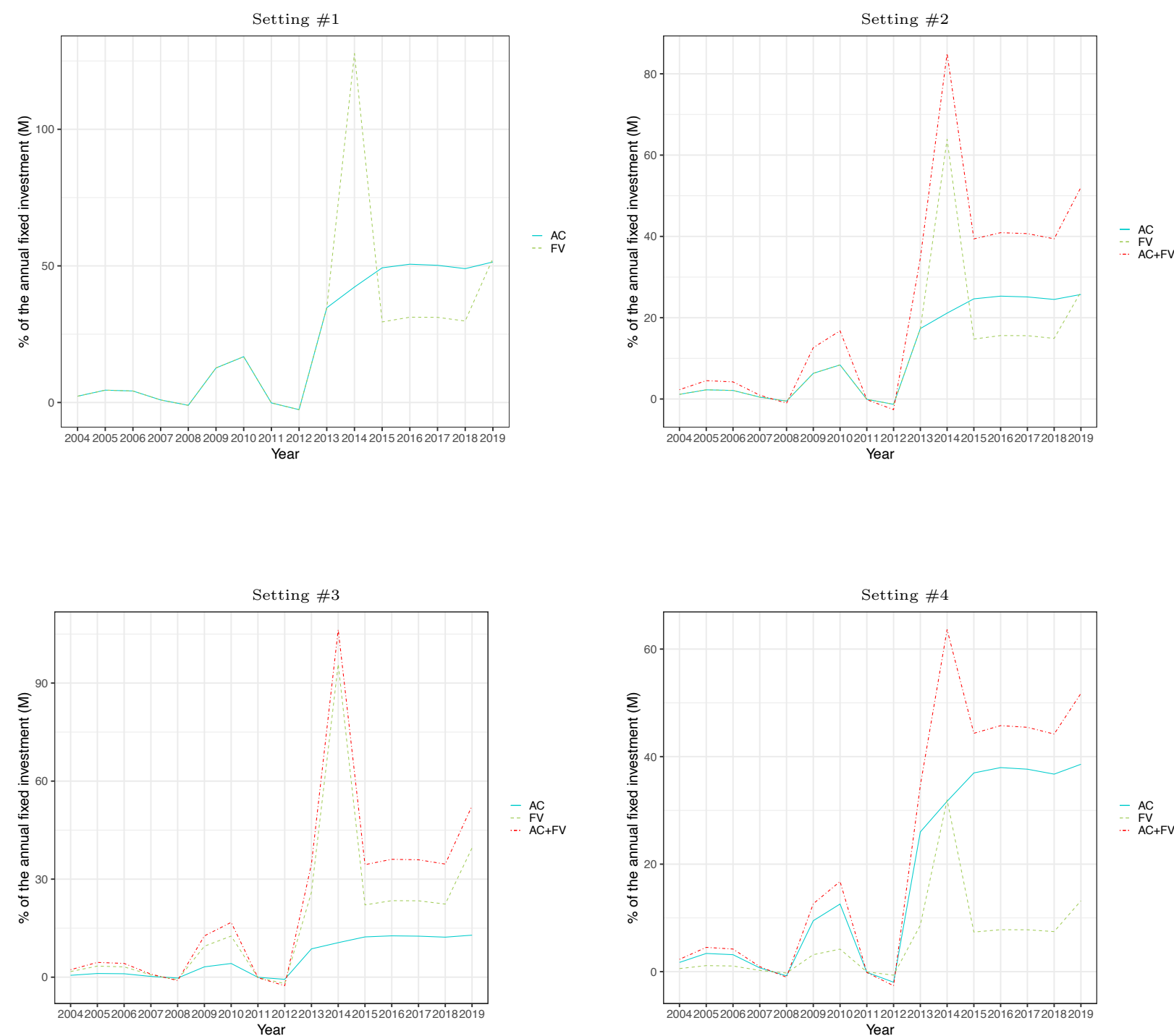

This figure reports the annual income (in \% of the annual fixed investment, $M$ ) for each setting: the case where the bank investment manager allocates the investment totally to AC or totally to FV (setting \#1); the case where the bank investment manager allocates $50 \%$ of the investment to $A C$ and $50 \%$ to $F V$ (setting \#2); the case where the bank investment manager decides to allocate $25 \%$ of the investment to AC and $75 \%$ to FV (setting \#3); and, finally the case where the bank investment manager allocates $75 \%$ of the investment to AC and $25 \%$ to $F V$ (setting \#4). 
Figure 4: Annual Comprehensive Income
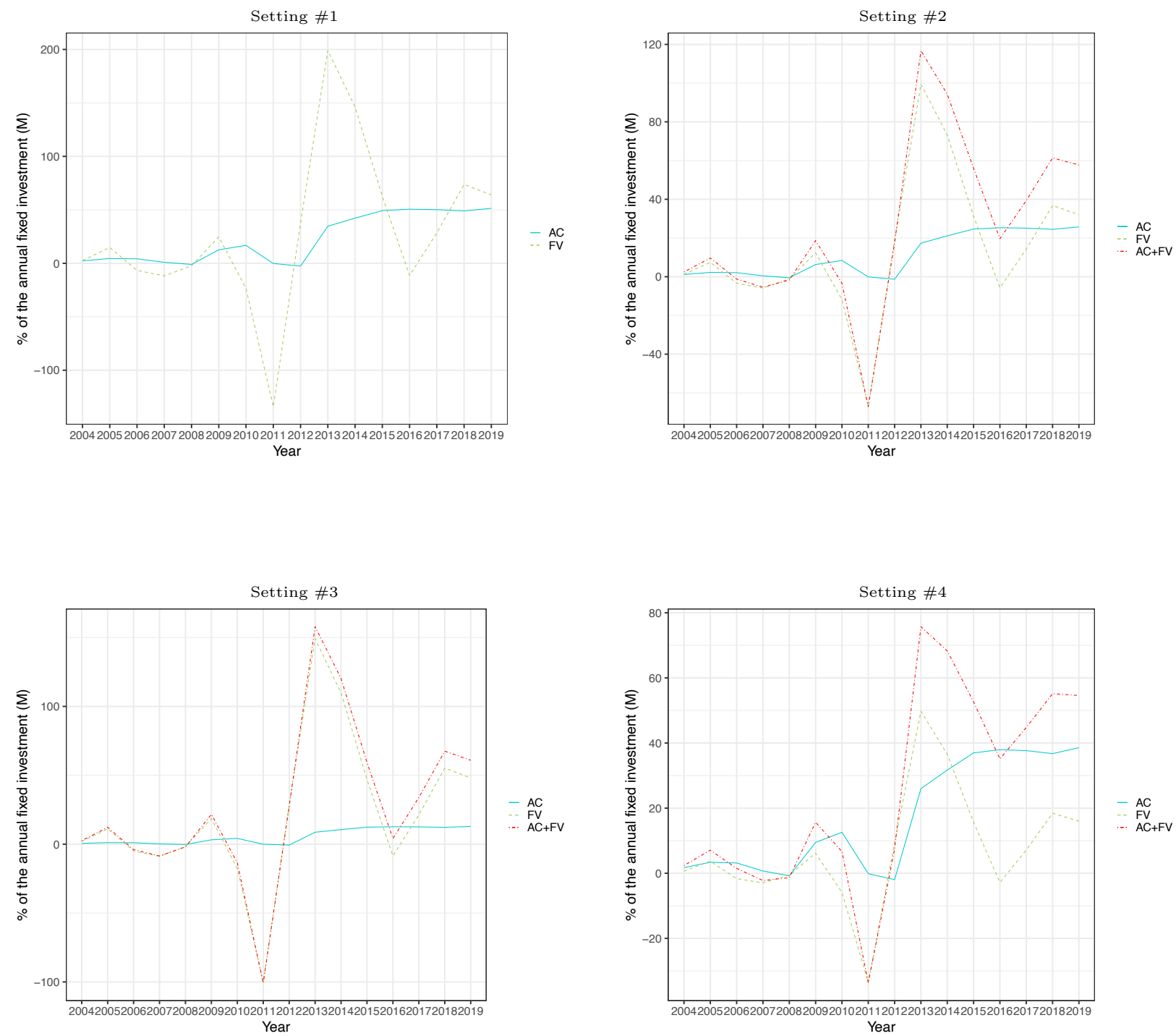

This figure reports the annual comprehensive income (in \% of the annual fixed investment, $M$ ) for each setting: the case where the bank investment manager allocates the investment totally to AC or totally to FV (setting \#1); the case where the bank investment manager allocates $50 \%$ of the investment to $A C$ and $50 \%$ to $F V$ (setting \#2); the case where the bank investment manager decides to allocate $25 \%$ of the investment to AC and $75 \%$ to FV (setting \#3); and, finally the case where the bank investment manager allocates $75 \%$ of the investment to AC and $25 \%$ to FV (setting \#4). 
should be noted that the biggest drop is observed in the case that the bank investment manager decides to allocate the investment totally to FV (setting \#1 when the allocation is all to $\mathrm{FV}$ a drop of $134.14 \%$ of $M$ is observed), and the lowest drop is observed when the bank investment manager decides to allocate the investment totally to AC (setting \#1 when the allocation is done all to $\mathrm{AC}$ and we observe a drop of $0.16 \%$ of $M$ ).

Looking just to the income (see Figure 3), in setting \#1, between 2004 and 2013, the income, originated each year, is always the same independently of the allocation type. In 2014 we observe a superior income originated at FV in comparison with the income originated at $\mathrm{AC}$ (see Figure 3). This results from realized gains, since the bonds acquired in 2010 and 2011 at the yields of $10.24 \%$ and 10.55\%, respectively, are sold in 2014 because the defined threshold is exceeded (the bond yield of 2014 is equal to $3.75 \%$ ). However, in 2015 (despite the gains, realized in 2004, having been reinvested at FV) we observe a decline (compared to the case where the investment is totally allocated to AC) in the income. This decline results from the margin drop due to the liquidation carried out in the previous year of 2014. We can also note that if the investment is totally allocated to FV we have more volatility than if the investment is totally allocated to AC: in the case that the investment is allocated totally to $\mathrm{FV}$ we observe an annual income standard deviation equal to $32.39 \%$ and a standard deviation equal to $22.67 \%$ in the case that the investment is made totally in AC. Still in setting \#1 and now regarding the comprehensive income (see Figure 4) we also found that the investment allocated to FV is much more volatile than the investment to AC. In fact, if the investment is totally made to FV the standard deviation of the annual comprehensive income is equal to $74.35 \%$ and, in turn, if the investment is allocated totally to AC this number falls to $22.67 \%$ (more than three times lower). Even if we look to the income we observe a similar pattern. This was somehow expected, since an asset classified at FV is subject to market variations.

The annual income and the annual comprehensive income (see Figure 3 and Figure 4, respectively) in settings \#2, \#3 and \#4 exhibit a similar behavior as observed in setting \#1 (differing only in the percentage that is allocated to $\mathrm{AC}$ and to $\mathrm{FV}$ ). The higher the percentage allocated to FV the more volatile will be the annual income and the annual comprehensive income of the investment.

In order to understand the most advantageous allocation, from the point of view of the bank investment manager, in addition to observing the annual variations of the income and the comprehensive income, it is important to compute (for the defined time horizon) the annual average value of the income and the comprehensive income. These results are presented in Figure 5 and Figure 6, respectively.

On the one hand, the maximum annual average income $(23.40 \%$ of $M)$ and the maximum annual average comprehensive income $(29.02 \%$ of $M$ ) are obtained in the case where the bank investment manager decides to allocate the investment totally to FV (see setting $\# 1$, allocation at FV, in Figure 5 and Figure 6, respectively). On the other hand, the minimum annual average income $(22.81 \%$ of $M)$ and the minimum annual average comprehensive income (22.81\% of $M$ ) are observed in the case where the bank investment manager allocates the investment totally to $\mathrm{AC}$ (see setting $\# 1$, allocation to $\mathrm{AC}$, in Figure 5 and Figure 6, respectively). 
Figure 5: Average Results - Income
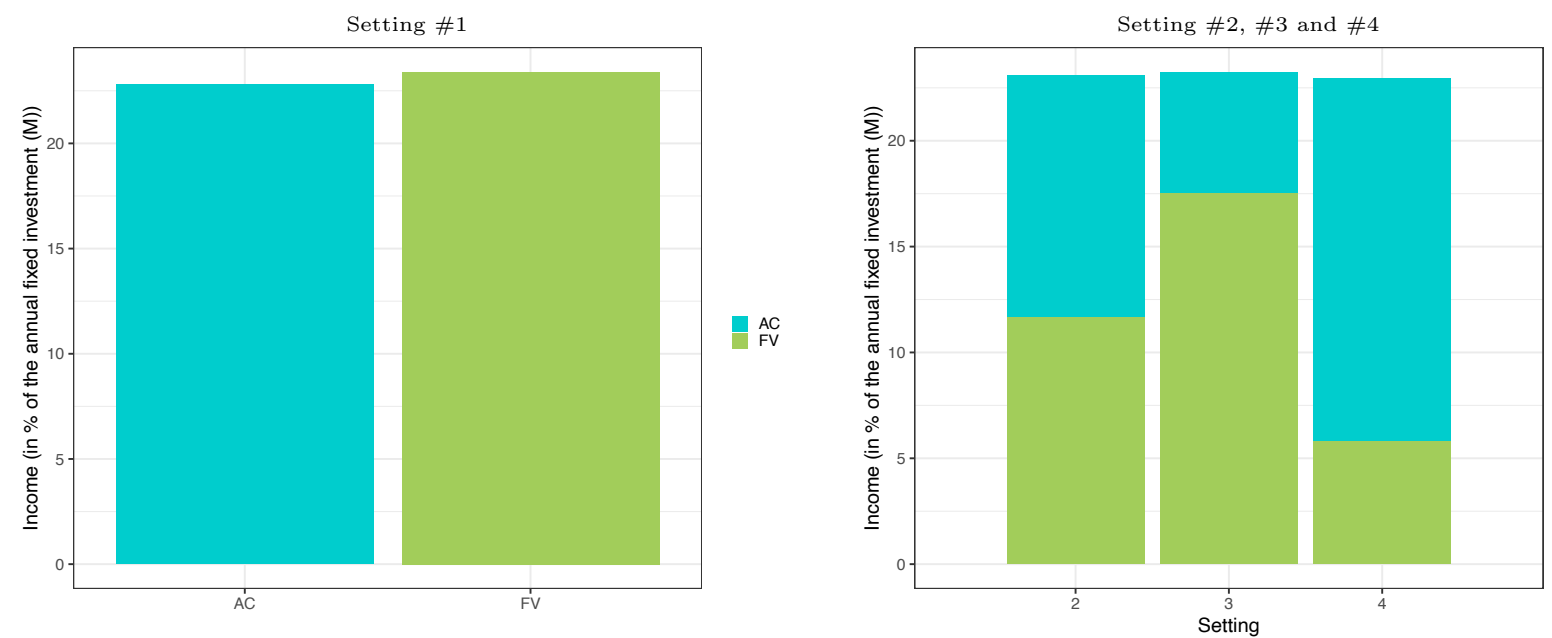

This figure reports the average results, for the time period 2003-2019, of the income (in \% of the annual fixed investment, $M)$ for each setting: the case where the bank investment manager allocates the investment totally to AC or totally to FV (setting \#1); the case where the bank investment manager allocates $50 \%$ of the investment to AC and $50 \%$ to FV (setting \#2); the case where the bank investment manager decides to allocate $25 \%$ of the investment to AC and $75 \%$ to $F V$ (setting \#3); and, finally the case where the bank investment manager allocates $75 \%$ of the investment to $A C$ and $25 \%$ to $F V$ (setting \#4).

\section{Figure 6: Average Results - Comprehensive Income}
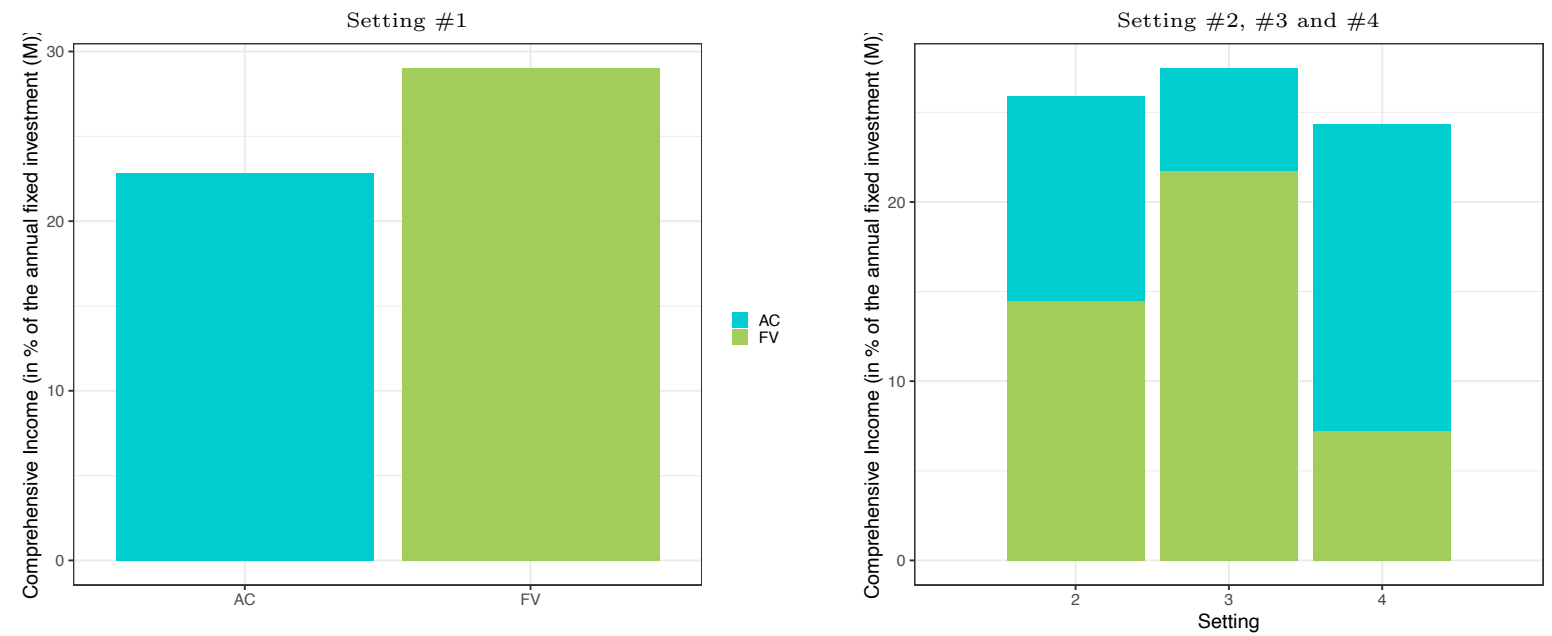

This figure reports the average results, for the time period 2003-2019, of the comprehensive income (in \% of the annual fixed investment, $M$ ) for each setting: the case where the bank investment manager allocates the investment totally to AC or totally to $F V$ (setting \#1); the case where the bank investment manager allocates $50 \%$ of the investment to AC and $50 \%$ to FV (setting \#2); the case where the bank investment manager decides to allocate $25 \%$ of the investment to AC and $75 \%$ to FV (setting \#3); and, finally the case where the bank investment manager allocates $75 \%$ of the investment to AC and $25 \%$ to FV (setting \#4). 
These numbers contrast with the settings where the investment manager decides to implement mixed allocations (settings \#2, \#3 and \#4, see Figure 5 and Figure 6): the annual average income in settings \#2, \#3 and \#4 is equal to $23.11 \%$ of $M, 23.25 \%$ of $M$ and $22.96 \%$ of $M$, respectively; in turn, the annual average comprehensive income in settings \#2, \#3 and \#4 is equal to $25.92 \%$ of $M, 27.47 \%$ of $M, 24.37 \%$ of $M$, respectively. According to these data we infer that the higher the allocation to FV the higher the annual average income and the annual average comprehensive income.

So given the assumptions under which this backtest was performed, clearly the best choice for the bank investment manager would be to allocate the investment totally to FV. Nevertheless, these results are dependent of two very important assumptions: the investment time horizon (in the backtest case seventeen years - from 2003 to 2019) and the value assigned to the threshold $(\tau)$ that defines when gains at FV should be realized (in the backtest $\tau=0.05$ ). Let us analyze more deeply the importance of these assumptions, focusing on setting \#1 (this without losing generality), where the bank investment manager decides to allocate the investment totally to $\mathrm{AC}$ or totally to $\mathrm{FV}$.

Regarding the investment time horizon, in practice we know that the bank investment manager has incentives to choose shorter time horizons. Instead of the seventeen-year investment period, let us consider three different time horizons: 3, 5 and 10 years. Considering a rolling-window approach (for further details see, e.g., DeMiguel et al. 2009), we compute the annual average income and the annual average comprehensive income, for the cases where the investment is allocated totally to AC or totally to FV. The results are reported in tables 2 to 4, for 3-year, 5-year and 10-year time horizons, respectively. Contrasting these results with the seventeen year's investment period (see setting \#1 in Figure 5 and Figure 6), we observe that the bank investment manager has a greater gain in deciding to allocate the investment totally to $\mathrm{FV}$ instead of to allocate the investment totally to AC: in the case of a 3-year time horizon (see Table 2) and considering the entire sample time period (2003-2019), the annual average income/comprehensive income, for the investment totally allocated to $\mathrm{AC}$, is equal to $7.69 \% / 7.69 \%$, and for the investment totally allocated to $\mathrm{FV}$, is equal to $10.57 \% / 14.19 \%$; for the case of a 5 -year time horizon (see Table 3), the investment totally allocated to AC originates an annual average income/comprehensive income equal to $24.21 \% / 24.21 \%$, and the investment totally allocated to FV originates an annual income/comprehensive income equal to $35.37 \% / 31.02 \%$, this considering the entire sample time period (2003-2019); finally, in the case of a 10-year time horizon (see Table 4) and considering the entire sample time period (2003-2019), the annual average income/comprehensive income, for the investment totally allocated to AC, is equal to $67.88 \% / 67.88 \%$, and for the investment totally allocated to $\mathrm{FV}$, is equal to $83.66 \% / 106.1 \%$.

Thereby, when the bank investment manager considers, as investment time horizon, the entire sample period, 2003-2019 (see setting \#1 in Figure 5 and Figure 6), she/he has an upside (from allocating the investment totally to $\mathrm{FV}$ in contrast with totally to $\mathrm{AC}$ ) of $0.58 \%$ in the annual average income, and $6.21 \%$ in the annual average comprehensive income. In turn, this upside is clearly greater in the cases that the investment time horizon is shorter: in the 3-year case (see Table 2), 2.89\% in the annual average income, 
and $6.50 \%$ in the annual average comprehensive income; for the 5 -year case (see Table 3 ), $11.17 \%$ in the annual average income, and $6.82 \%$ in annual average comprehensive income; in the 10-year case (see Table 4), $15.79 \%$ in the annual average income, and $38.20 \%$ in the annual average comprehensive income. We highlight that these results, obviously, are dependent on the yields' trajectory. In hindsight, we know that, in the data set under analysis, there was a great downward trajectory for the bond yields from 2012 to 2015 (see Figure 2), which allows to the realization of gains at FV.

In Table 5 we report the annual average (for the seventeen years' sample) income and annual average comprehensive income, for different values of $\tau$ (the threshold that determines if the bank investment manager realizes gains and reinvests them, at $\mathrm{FV}$, in the following period). Of course the $\tau$ value does not have any influence in the annual income and the annual comprehensive income when the investment is totally allocated to AC. Thus, the annual average income and the annual average comprehensive income are always equal to $22.81 \%$ (see Figure 5 and Figure 6, respectively) independently of the chosen $\tau$ value. From the results presented in Table 5, we observe that for $\tau$ equal to $0.01,0.02,0.03,0.04$ and 0.06 , the annual average income is always lower in the case that the investment is totally allocated to FV (in contrast with the case where the investment is allocated totally to $\mathrm{AC}$ ).

Analyzing the variations in the comprehensive income, only with $\tau$ equal to 100 basis points the annual average comprehensive income at $\mathrm{FV}$ is lower than the annual average comprehensive income at AC. Note that with values of $\tau$ equal or greater than 700 basis points, the bank investment manager reaches the higher values of annual average comprehensive income (higher than the initial case considered of $\tau=0.05$, see Table 5). With $\tau$ equal to 900 basis points the bank manager obtains the best values of annual average income $(25.79 \%$ of $M)$ and annual average comprehensive income (31.95\% of $M)$. Somehow, these are expected results. The lower the $\tau$ value then the lower are the possible gains that a bond classified at FV can originate which, in turn, is an incentive to allocate the bond to AC instead of allocate it to FV. An analogous reasoning can be applied to the case of higher $\tau$ values but with an upper bound (note that with $\tau$ equal to 1000 basis points the annual average income obtained with the allocation totally made to FV is the same as if the allocation is totally made to $\mathrm{AC}$ ).

The analysis of the tradeoff between classifying a bond at $\mathrm{AC}$ or at FV constitutes, as we can see from the backtest's results, a crucial decision for the bank investment manager. It is therefore important to have a quantitative model that allows the bank investment manager to systematically identify efficient allocations ( $\mathrm{AC}$ or $\mathrm{FV}$ ) according to a risk-return target. The income originated by the investment presents itself as a good return target. As a risk target we suggest to consider the downside of the comprehensive income, which effectively impacts the bank's own funds and regulatory capital ratios. In the next section we propose to build and analyze a model, over the space of all feasible allocations to $\mathrm{AC}$ or $\mathrm{FV}$, in which, on the one hand, the bank investment manager intends to maximize the income and, on the other hand, she/he intends to minimize the downside of the comprehensive income. 
Table 2: Annual Average Income and Comprehensive Income for a 3-year investment time horizon

\begin{tabular}{|c|c|c|c|}
\hline Investment Time Horizon & Allocation Type & Income & Comprehensive Income \\
\hline \multirow{2}{*}{ 2003-2005 } & $\mathrm{AC}$ & $3.407 \%$ & $3.407 \%$ \\
\hline & $\mathrm{FV}$ & $3.407 \%$ & $8.723 \%$ \\
\hline \multirow{2}{*}{$2004-2006$} & $\mathrm{AC}$ & $2.367 \%$ & $2.367 \%$ \\
\hline & FV & $2.367 \%$ & $1.427 \%$ \\
\hline \multirow{2}{*}{$2005-2007$} & $\mathrm{AC}$ & $0.414 \%$ & $0.414 \%$ \\
\hline & $\mathrm{FV}$ & $0.414 \%$ & $-4.642 \%$ \\
\hline \multirow{2}{*}{$2006-2008$} & $\mathrm{AC}$ & $0.014 \%$ & $0.014 \%$ \\
\hline & FV & $0.014 \%$ & $-2.263 \%$ \\
\hline \multirow{2}{*}{$2007-2009$} & $\mathrm{AC}$ & $2.526 \%$ & $2.526 \%$ \\
\hline & $\mathrm{FV}$ & $2.526 \%$ & $4.446 \%$ \\
\hline \multirow{2}{*}{$2008-2010$} & $\mathrm{AC}$ & $3.854 \%$ & $3.854 \%$ \\
\hline & FV & $3.854 \%$ & $-3.011 \%$ \\
\hline \multirow{2}{*}{ 2009-2011 } & $\mathrm{AC}$ & $2.375 \%$ & $2.375 \%$ \\
\hline & $\mathrm{FV}$ & $2.375 \%$ & $-27.22 \%$ \\
\hline \multirow{2}{*}{$2010-2012$} & $\mathrm{AC}$ & $5.108 \%$ & $5.108 \%$ \\
\hline & $\mathrm{FV}$ & $5.108 \%$ & $-8.584 \%$ \\
\hline \multirow{2}{*}{ 2011-2013 } & $\mathrm{AC}$ & $11.23 \%$ & $11.23 \%$ \\
\hline & $\mathrm{FV}$ & $11.23 \%$ & $38.27 \%$ \\
\hline \multirow{2}{*}{$2012-2014$} & $\mathrm{AC}$ & $10.39 \%$ & $10.39 \%$ \\
\hline & $\mathrm{FV}$ & $33.48 \%$ & $43.68 \%$ \\
\hline \multirow{2}{*}{ 2013-2015 } & $\mathrm{AC}$ & $5.953 \%$ & $5.953 \%$ \\
\hline & $\mathrm{FV}$ & $5.953 \%$ & $25.84 \%$ \\
\hline \multirow{2}{*}{ 2014-2016 } & $\mathrm{AC}$ & $3.530 \%$ & $3.530 \%$ \\
\hline & $\mathrm{FV}$ & $3.530 \%$ & $3.318 \%$ \\
\hline \multirow{2}{*}{$2015-2017$} & $\mathrm{AC}$ & $2.916 \%$ & $2.916 \%$ \\
\hline & $\mathrm{FV}$ & $2.916 \%$ & $1.824 \%$ \\
\hline \multirow{2}{*}{ 2016-2018 } & $\mathrm{AC}$ & $3.776 \%$ & $3.776 \%$ \\
\hline & $\mathrm{FV}$ & $3.776 \%$ & $14.33 \%$ \\
\hline \multirow{2}{*}{ 2017-2019 } & $\mathrm{AC}$ & $3.630 \%$ & $3.630 \%$ \\
\hline & $\mathrm{FV}$ & $3.630 \%$ & $17.35 \%$ \\
\hline
\end{tabular}

This table reports the annual average income and the annual average comprehensive income (in \% of the annual fixed investment, $M$ ), for both cases where the bank investment manager decides to allocate the bonds' investment totally to AC or totally to $F V$ (setting \#1). The results are reported to a 3-year investment time horizon. 
Table 3: Annual Average Income and Comprehensive Income for a 5-year investment time horizon

\begin{tabular}{|c|c|c|c|}
\hline Investment Time Horizon & Allocation Type & Income & Comprehensive Income \\
\hline \multirow{2}{*}{$2003-2007$} & $\mathrm{AC}$ & $2.991 \%$ & $2.991 \%$ \\
\hline & $\mathrm{FV}$ & $2.991 \%$ & $-0.2343 \%$ \\
\hline \multirow{2}{*}{ 2004-2008 } & $\mathrm{AC}$ & $1.041 \%$ & $1.041 \%$ \\
\hline & $\mathrm{FV}$ & $1.041 \%$ & $-2.143 \%$ \\
\hline \multirow{2}{*}{ 2005-2009 } & $\mathrm{AC}$ & $2.046 \%$ & $2.046 \%$ \\
\hline & $\mathrm{FV}$ & $2.046 \%$ & $1.594 \%$ \\
\hline \multirow{2}{*}{ 2006-2010 } & $\mathrm{AC}$ & $4.254 \%$ & $4.254 \%$ \\
\hline & FV & $4.254 \%$ & $-2.389 \%$ \\
\hline \multirow{2}{*}{$2007-2011$} & $\mathrm{AC}$ & $4.260 \%$ & $4.260 \%$ \\
\hline & $\mathrm{FV}$ & $4.260 \%$ & $-23.65 \%$ \\
\hline \multirow{2}{*}{$2008-2012$} & $\mathrm{AC}$ & $5.295 \%$ & $5.295 \%$ \\
\hline & $\mathrm{FV}$ & $5.295 \%$ & $-15.26 \%$ \\
\hline \multirow{2}{*}{ 2009-2013 } & $\mathrm{AC}$ & $8.794 \%$ & $8.794 \%$ \\
\hline & $\mathrm{FV}$ & $8.794 \%$ & $18.86 \%$ \\
\hline \multirow{2}{*}{$2010-2014$} & $\mathrm{AC}$ & $13.70 \%$ & $13.70 \%$ \\
\hline & $\mathrm{FV}$ & $35.07 \%$ & $42.66 \%$ \\
\hline \multirow{2}{*}{$2011-2015$} & $\mathrm{AC}$ & $17.80 \%$ & $17.80 \%$ \\
\hline & $\mathrm{FV}$ & $34.36 \%$ & $44.63 \%$ \\
\hline \multirow{2}{*}{$2012-2016$} & $\mathrm{AC}$ & $14.79 \%$ & $14.79 \%$ \\
\hline & $\mathrm{FV}$ & $21.52 \%$ & $25.98 \%$ \\
\hline \multirow{2}{*}{ 2013-2017 } & $\mathrm{AC}$ & $9.135 \%$ & $9.135 \%$ \\
\hline & $\mathrm{FV}$ & $9.135 \%$ & $14.39 \%$ \\
\hline \multirow{2}{*}{ 2014-2018 } & $\mathrm{AC}$ & $6.544 \%$ & $6.544 \%$ \\
\hline & $\mathrm{FV}$ & $6.544 \%$ & $15.79 \%$ \\
\hline \multirow{2}{*}{ 2015-2019 } & $\mathrm{AC}$ & $6.187 \%$ & $6.187 \%$ \\
\hline & $\mathrm{FV}$ & $6.187 \%$ & $19.66 \%$ \\
\hline
\end{tabular}

This table reports the annual average income and the annual average comprehensive income (in \% of the annual fixed investment, $M$ ), for both cases where the bank investment manager decides to allocate the bonds' investment totally to $A C$ or totally to $F V$ (setting \#1). The results are reported to a 5-year investment time horizon. 
Table 4: Annual Average Income and Comprehensive Income for a 10-year investment time horizon

\begin{tabular}{|c|c|c|c|}
\hline Investment Time Horizon & Allocation Type & Income & Comprehensive Income \\
\hline \multirow{2}{*}{$2003-2012$} & $\mathrm{AC}$ & $4.174 \%$ & $4.174 \%$ \\
\cline { 2 - 4 } & $\mathrm{FV}$ & $4.174 \%$ & $-10.94 \%$ \\
\hline \multirow{2}{*}{$2004-2013$} & $\mathrm{AC}$ & $6.081 \%$ & $6.081 \%$ \\
\hline \multirow{2}{*}{$2005-2014$} & $\mathrm{FV}$ & $6.081 \%$ & $10.32 \%$ \\
\hline \multirow{2}{*}{$2006-2015$} & $\mathrm{AC}$ & $8.967 \%$ & $8.967 \%$ \\
\hline \multirow{2}{*}{$2007-2016$} & $\mathrm{FV}$ & $18.46 \%$ & $25.39 \%$ \\
\hline \multirow{2}{*}{$2008-2017$} & $\mathrm{AC}$ & $13.35 \%$ & $13.35 \%$ \\
\hline \multirow{2}{*}{$2009-2018$} & $\mathrm{FV}$ & $20.60 \%$ & $31.66 \%$ \\
\hline \multirow{2}{*}{$2010-2019$} & $\mathrm{AC}$ & $17.29 \%$ & $17.29 \%$ \\
\hline & $\mathrm{FV}$ & $22.72 \%$ & $28.83 \%$ \\
\hline & $\mathrm{AC}$ & $20.37 \%$ & $20.37 \%$ \\
\hline & $\mathrm{FV}$ & $23.67 \%$ & $29.58 \%$ \\
\hline & $\mathrm{AC}$ & $22.85 \%$ & $22.85 \%$ \\
\hline & $\mathrm{FV}$ & $24.01 \%$ & $34.80 \%$ \\
\hline & $\mathrm{AC}$ & $27.59 \%$ & $27.59 \%$ \\
\hline
\end{tabular}

This table reports the annual average income and the annual average comprehensive income (in \% of the annual fixed investment, $M$ ), for both cases where the bank investment manager decides to allocate the bonds' investment totally to AC or totally to $F V$ (setting \#1). The results are reported to a 10-year investment time horizon. 
Table 5: Annual Average Income and Comprehensive Income for Different $\tau$ values

\begin{tabular}{|c|c|c|}
\hline Threshold & Income & Comprehensive Income \\
\hline $\boldsymbol{\tau}=\mathbf{0 . 0 1}$ & $18.63 \%$ & $19.45 \%$ \\
\hline $\boldsymbol{\tau}=\mathbf{0 . 0 2}$ & $21.52 \%$ & $23.46 \%$ \\
\hline $\boldsymbol{\tau}=\mathbf{0 . 0 3}$ & $19.34 \%$ & $25.06 \%$ \\
\hline $\boldsymbol{\tau}=\mathbf{0 . 0 4}$ & $21.62 \%$ & $26.96 \%$ \\
\hline $\boldsymbol{\tau}=\mathbf{0 . 0 5}$ & $23.40 \%$ & $29.02 \%$ \\
\hline $\boldsymbol{\tau}=\mathbf{0 . 0 6}$ & $22.04 \%$ & $29.02 \%$ \\
\hline $\boldsymbol{\tau}=\mathbf{0 . 0 7}$ & $23.93 \%$ & $31.33 \%$ \\
\hline $\boldsymbol{\tau}=\mathbf{0 . 0 8}$ & $24.50 \%$ & $31.33 \%$ \\
\hline $\boldsymbol{\tau}=\mathbf{0 . 0 9}$ & $25.79 \%$ & $31.95 \%$ \\
\hline $\boldsymbol{\tau}=\mathbf{0 . 1 0}$ & $22.81 \%$ & $31.95 \%$ \\
\hline
\end{tabular}

This table reports the annual average income and the annual average comprehensive income (in $\%$ of the annual fixed investment, $M)$, for the case where the bank investment manager decides to allocate the bonds' investment totally to FV (setting \#1), for 10 different thresholds $(\tau)$ that determine when gains should or should not be realized.

\subsection{A Bi-Objective Model and the Pareto Front}

In this section we propose a bi-objective model designed over the feasible space of all possible allocations (to $\mathrm{AC}$ or to $\mathrm{FV}$ ), in which the bank investment manager maximizes the annual income and minimizes the annual downside of the comprehensive income. Such a framework allows the bank investment manager to directly identify efficient allocations according to two defined objectives. As the risk target we suggest to make use of a downside risk measure, since downside risk measures realistically only account for the negative part of the deviations from a certain predefined level (for a detailed survey on downside risk measures, see Nawrocki 1999 and Estrada 2006). Roy (1952) was one of the earliest contributors (with the Roy's safety first principle) for further development of downside risk measures. Posteriorly, Bawa (1975) and Fishburn (1977) introduced the lower partial moments. Interestingly, the lower partial moments are no more than a generalization of the semivariance, proposed previously by Markowitz (1959). In fact, Markowitz (1959) stated that the semivariance is a much more plausible risk measure than the variance. However, for computational reasons, the semivariance is often neglected (Estrada, 2008).

In this paper, as a measure of the downside of the comprehensive income, we make use of the semivariance (also known as the lower partial measure of degree 2; see Bawa 1975 and Fishburn 1977). Before we show how the semivariance of the annual comprehensive income can be computed, let us introduce some more notation. Let $c\left(w^{(A C)}, w^{(F V)}\right)=$ $\left[c_{1}\left(w^{(A C)}, w^{(F V)}\right), \ldots, c_{s-1}\left(w^{(A C)}, w^{(F V)}\right)\right]^{\top}$ represent the $(s-1) \times 1$ vector of the annual comprehensive incomes. Thereby each annual comprehensive income is given by 


$$
c_{i-1}\left(w^{(A C)}, w^{(F V)}\right)=\sum_{j \in\{1, \ldots, i-1\}} z_{i, j}^{(A C)}+z_{i, j}^{(F V)}, \forall i=2, \ldots, s .
$$

Accordingly, we can compute the semivariance of the annual comprehensive income, $S M V\left(c\left(w^{(A C)}, w^{(F V)}\right)\right)$, as

$$
S M V\left(c\left(w^{(A C)}, w^{(F V)}\right)\right)=\frac{1}{s-1} \sum_{i \in\{1, \ldots, s-1\}} \min \left(c_{i}\left(w^{(A C)}, w^{(F V)}\right)-B, 0\right)^{2},
$$

where $B$ represents a benchmark target. In this paper we establish $B$ as the sample mean of the annual comprehensive income distribution. Therefore,

$$
B=\frac{1}{s-1} \sum_{i \in\{1, \ldots, s-1\}} c_{i}\left(w^{(A C)}, w^{(F V)}\right)
$$

Defining the semivariance of the annual comprehensive income as in Equation (15) leads to an endogenous definition, i.e., a change in the bonds' investment allocation $\left(w^{(A C)}\right.$ and $w^{(F V)}$ ) changes the years when the annual comprehensive income underperforms its mean (the mean is also affected), which in turn changes the elements of the annual comprehensive income semivariance.

Defining the annual average income, $A V I\left(w^{(A C)}, w^{(F V)}\right)$, as

$$
A V I\left(w^{(A C)}, w^{(F V)}\right)=\frac{1}{s-1} \sum_{i \in I} \sum_{j \in J} x_{i, j}^{(A C)}+x_{i, j}^{(F V)},
$$

the bank investment manager can decide the efficient allocation (to $\mathrm{AC}$ or to $\mathrm{FV}$ ) by finding the solution of the following bi-objective problem

$$
\begin{array}{cl}
\max _{\left(w^{(A C)}, w^{(F V)}\right) \in \mathbb{R}^{2}} & A V I\left(w^{(A C)}, w^{(F V)}\right) \\
\min _{\left(w^{(A C)}, w^{(F V)}\right) \in \mathbb{R}^{2}} & S M V\left(c\left(w^{(A C)}, w^{(F V)}\right)\right) \\
\text { subject to } & w^{(A C)}+w^{(F V)}=1 .
\end{array}
$$

The solution of Problem (18) is given in the form of a Pareto front. $\left(w_{*}^{(A C)}, w_{*}^{(F V)}\right) \in \mathbb{R}^{2}$ belongs to the Pareto frontier if it corresponds to a nondominated point, i.e., there is no other feasible point $\left(w^{(A C)}, w^{(F V)}\right) \in \mathbb{R}^{2}$ such that

$$
\begin{aligned}
A V I\left(w^{(A C)}, w^{(F V)}\right) & >A V I\left(w_{*}^{(A C)}, w_{*}^{(F V)}\right) \\
& \bigwedge \\
S M V\left(c\left(w^{(A C)}, w^{(F V)}\right)\right) & <S M V\left(c\left(w_{*}^{(A C)}, w_{*}^{(F V)}\right)\right) .
\end{aligned}
$$


We have no access to the derivatives of both the objective functions of Problem (18), since both functions are endogenous. Therefore, we solve Problem (18) using a derivativefree algorithm. Among the derivative-free algorithms available for multi-objective optimization, direct multisearch ${ }^{8}$ performs the best in a robust numerical exercise (test set of more than 100 problems) reported in Custódio et al. (2011). Moreover, direct multisearch has even outperformed the popular non-dominated sorting genetic algorithm (Deb et al., 2002), in the same numerical experiment (Custódio et al., 2011). Thus, we have chosen this algorithm to find the Pareto front solution of Problem (18).

Using the entire available time window (2003-2019) to estimate the inputs' parameters, the solution of Problem (18) is presented in Figure 7. Now, the bank investment manager has a way to find efficient allocations (to AC or to FV) according her/his own risk-return preferences. Thereby, e.g., $w_{10}=\left[w_{10}^{(A C)}, w_{10}^{(F V)}\right]^{\top}$, where $w_{10}^{(A C)}=0.0441$ and $w_{10}^{(F V)}=$ 0.9559 , is the allocation corresponding to the top ${ }^{9} 10 \%$ of the $S M V$ (see Figure 7 ), $w_{50}=$ $\left[w_{50}^{(A C)}, w_{50}^{(F V)}\right]^{\top}$, where $w_{50}^{(A C)}=0.2667$ and $w_{50}^{(F V)}=0.7333$, is the allocation corresponding to the top $50 \%$ of the $S M V$ (see Figure 7), and finally $w_{90}=\left[w_{90}^{(A C)}, w_{90}^{(F V)}\right]^{\top}$, where $w_{90}^{(A C)}=0.7062$ and $w_{90}^{(F V)}=0.2938$, is the allocation corresponding to the top $90 \%$ of the $S M V$ (see Figure 7). We observe that the proposed framework incorporates the intuition that the greater the allocation to $\mathrm{FV}$, the greater the expected risk and in turn the greater the expected return.

Corresponding this framework to a stochastic optimization framework, it is important to take into account the results' sensitivity to the estimation error present in both the objectives. Particularly, we know that the semivariance, being an asymmetric risk measure, is many times more sensitive to estimation error, than symmetric risk measures that make use of more information (Satchell, 2010). One possible way to mitigate this estimation error is through a resampling methodology as proposed by Michaud and Michaud (1998). The idea is straightforward. The bank investment manager generates different scenarios for which a solution of the proposed model is found. The average of the obtained solutions corresponds to the optimal efficient solution. But how to simulate the different scenarios for the complex problem that we have in hands? In the next section we address this issue by presenting and exemplifying a possible approach.

\subsection{Stochastic Simulation and Out-of-Sample Performance}

Simulating future scenarios is an arduous task which mainly requires a significant amount of modeling. In this section we will consider just a possible way to simulate future scenarios in our framework. We assume only one general premise: that the future resembles the past. Of course this premise is quite debatable, but our aim here it is just to have a systematic way of simulating scenarios instead of predicting the future. We are interested in simulating different possible "futures" that are generated according to the historical

\footnotetext{
${ }^{8} \mathrm{~A}$ derivative-free solver based on direct multisearch, dms, is publicly available under request at http://www.mat.uc.pt/dms/.

${ }^{9}$ Let $c d f$ be the normalized cumulative distribution function of $S M V\left(w^{(A C)}, w^{(F V)}\right)$. Then, the top $\mathrm{x} \%$ of risk is defined by the allocation $\left(w^{(A C)}, w^{(F V)}\right)$ such that $c d f\left(w^{(A C)}, w^{(F V)}\right)>=x \%$.
} 
Figure 7: Pareto Front

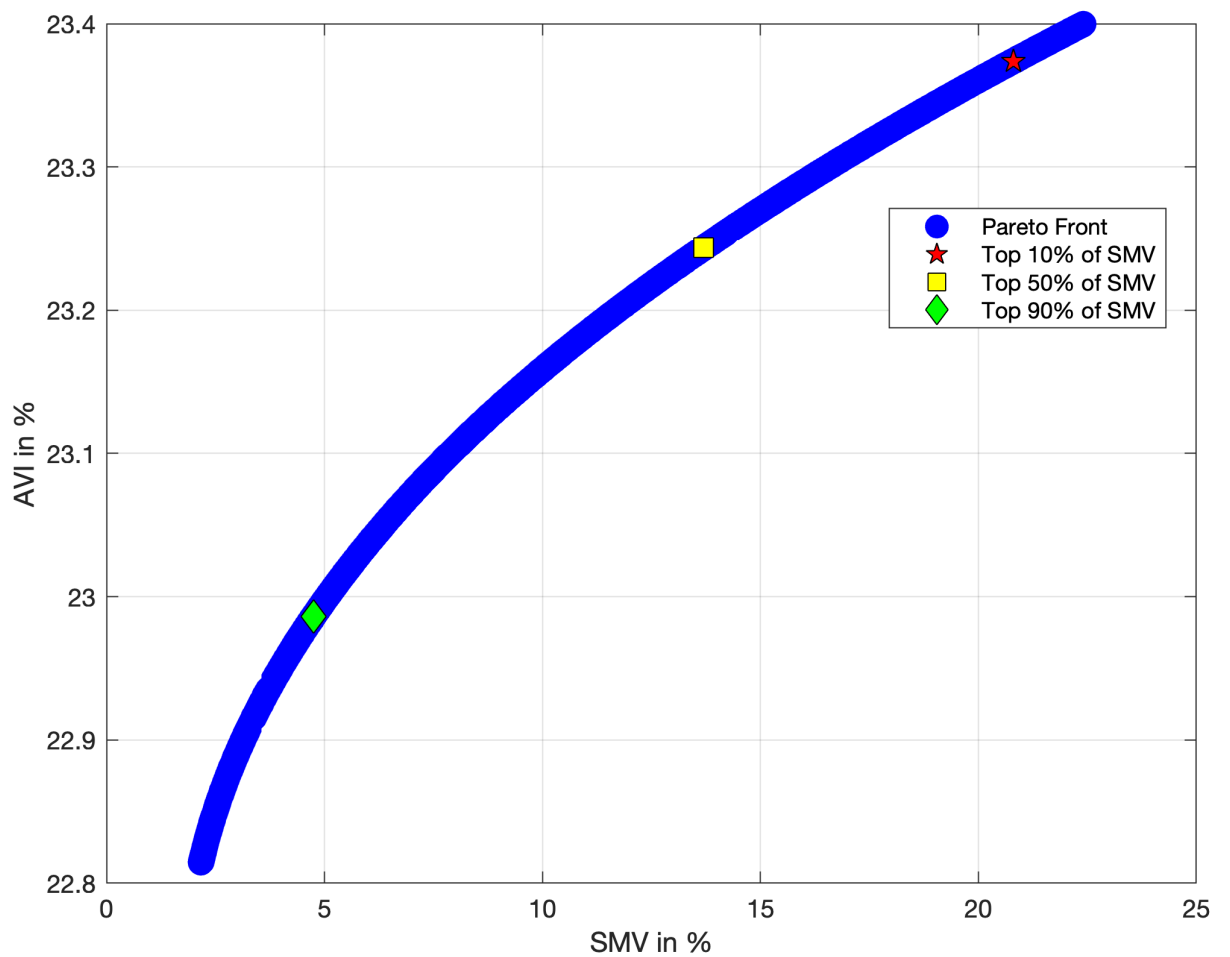

This figure reports the Pareto front, solution of Problem (18), using all the sample time period (2003-2019) for the input parameters' estimation. The threshold, $\tau$, used for the computation of the annual income at FV (see Equation (12)), was equal to 500 basis points. In this figure are also plotted the allocations that correspond to the top $10 \%, 50 \%$ and $90 \%$ of risk. 
available information. On one side, we need to simulate the yields and funding rates (incorporating the observed historical correlation between these two rates) and on the other side we need to simulate the ratings dynamics.

Regarding the simulation of the yields and funding rates, in this paper, we make use of a correlated mean-reverting process. Since our aim is to simulate (not to predict) different possible future states that somehow are a mirror of the past information, we will not allow negative rates and thereby we decided to make use of a squared Bessel stochastic process (Chou and Lin, 2006). The squared Bessel stochastic process is the basis of the Cox-Ingersoll-Ross model (Cox et al., 1985) and it is well-known in the financial literature as the CIR process. Given an interest rate, $r_{t}$, a CIR process can be defined by the following stochastic differential equation

$$
d r_{t}=\alpha\left(\mu-r_{t}\right) d t+\sigma \sqrt{r_{t}} d W_{t}
$$

where $\alpha$ is the mean reverting speed, $\mu$ is the mean reverting level and $\left\{W_{t}, t \geq 0\right\}$ represents a standard Brownian motion. The interest rate, $r_{t}$, thus follows a diffusion process with drift $\alpha\left(\mu-r_{t}\right)$ (it is linear and ensures the mean reverting property) and diffusion $r_{t} \sigma^{2}$ (it is proportional to the interest rate and ensures the positiveness of $r_{t}$ ). If $2 \alpha \mu \geq \sigma^{2}$ (with $\alpha, \mu, \sigma \geq 0$ ), the CIR process defined by Equation (20) has a marginal density that is gamma distributed (Cox et al., 1985). Following Cox et al. (1985) and Kladivko (2007), given $r_{t}$ (at time $t$ ) the density of $r_{t+\Delta t}$ (at time $t+\Delta t$ ) is given by

$$
p\left(r_{t+\Delta t} \mid r_{t} ; \alpha, \mu, \sigma, \Delta t\right)=c e^{-u-v}\left(\frac{u}{v}\right)^{(q / 2)} I_{q}(2 \sqrt{u v})
$$

with $c=\frac{2 \alpha}{\alpha^{2}\left(1-e^{\alpha \Delta t}\right)}, u=c r_{t} e^{\alpha \Delta t}, v=c r_{t+\Delta t}, q=\frac{2 \alpha \mu}{\sigma^{2}}-1$, and $I_{q}(2 \sqrt{u v})$ is the modified Bessel function of the first kind and order $q$ (for further details see, e.g., Arfken and Weber 2012). The transition density given by Equation (21) was for the first time derived by Feller (1951). Given this closed-form expression for the transition density it is straightforward to estimate the parameters $\alpha, \mu$ and $\sigma$ by maximum likelihood. A detailed implementation, in MATLAB ${ }^{\circledR}$, of how to proceed can be found in Kladivko (2007).

Assuming that the yields and the funding rates follow

$$
d y_{t}=\alpha^{y}\left(\mu^{y}-y_{t}\right) d t+\sigma^{y} \sqrt{y_{t}} d W_{t}^{y}
$$

and

$$
d f_{t}=\alpha^{f}\left(\mu^{f}-f_{t}\right) d t+\sigma^{y} \sqrt{f_{t}} d W_{t}^{f},
$$

respectively, and following Kladivko (2007), we have calibrated through maximum likelihood (using as initial estimates for the optimizing procedure, the estimates obtained through ordinary least squares) Equation (22) and Equation (23). Using all the available historical information, monthly data from 2003 to 2019, the monthly parameters estimated were: $\alpha^{y}=1.614, \alpha^{f}=1.588, \mu_{y}=0.03023, \mu_{f}=0.01023, \sigma_{y}=0.2735$, $\sigma_{f}=0.2033$ and $E\left[d W_{t}^{y} d W_{t}^{f}\right]=\rho d t=0.6539 d t$. 
Now we can use Equation (22) and Equation (23) to simulate different future states for the yields and funding rates. As we want to take into account the historical correlation between the yields and the funding rates, instead of simulating, separately, each one of the equations (Equation (22) and Equation (23)), we consider a vector-valued CIR process of the form

$$
\begin{gathered}
d R_{t}=\alpha\left[\mu-R_{t}\right] d t+\Sigma \sqrt{R_{t}} d W_{t} \Longleftrightarrow \\
{\left[\begin{array}{c}
d y_{t} \\
d f_{t}
\end{array}\right]=\left[\begin{array}{cc}
\alpha^{y} & 0 \\
0 & \alpha^{f}
\end{array}\right]\left(\left[\begin{array}{l}
\mu^{y} \\
\mu^{f}
\end{array}\right]-\left[\begin{array}{c}
y_{t} \\
f_{t}
\end{array}\right]\right) d t+\left[\begin{array}{cc}
\sigma_{y} \sqrt{y_{t}} & 0 \\
0 & \sigma_{f} \sqrt{f_{t}}
\end{array}\right]\left[\begin{array}{l}
d W_{t}^{y} \\
d W_{t}^{f}
\end{array}\right],}
\end{gathered}
$$

where $E\left[d W_{t}^{y} d W_{t}^{f}\right]=\rho d t$. Therefore, future yields and funding rates can be simulated, according to Equation (24), following discretization in time by a forward Euler approach (see Deelstra and Delbaen 1998, for further details). Through discretization negative values can occur. One possible way to handle the negative values is by means of the Higham-Mao method (Higham and Mao, 2005). Assuming that $t=0$ is the time period corresponding to the last sample observation (December 2019), Figure 8 presents one simulated path (for 10 years) of the yields and funding rates.

Figure 8: Simulated Path of the Yields and Funding rates

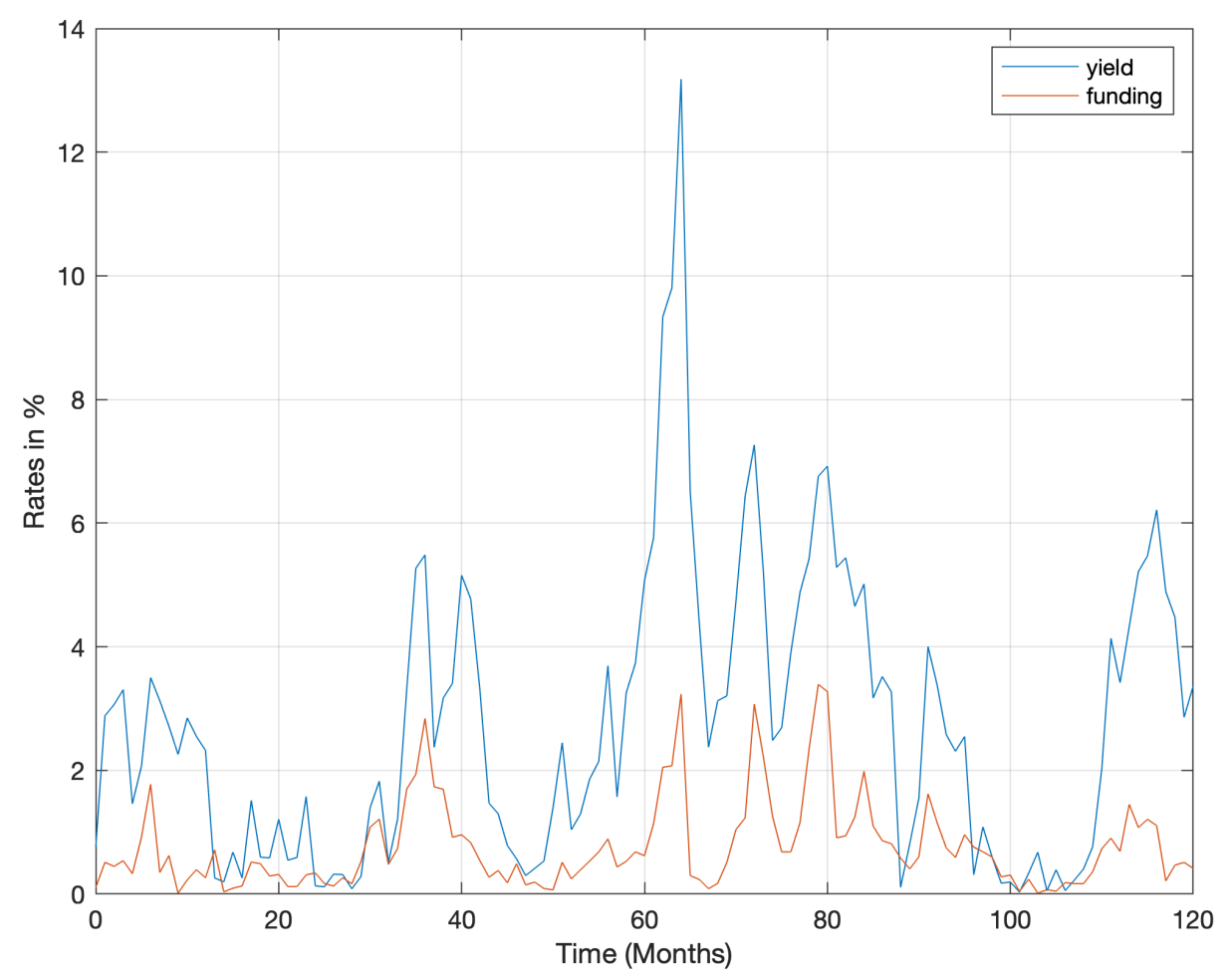

This figure reports one simulated path of the yields and funding rates. We assume that the yields and funding rates follow the dynamics described by Equation (24). The first time period, $t=0$, corresponds to the last historical sample observation (December 2019). 
In order to simulate the ratings dynamics, we constructed an ordered response model (Mckelvey and Zavoina, 1975). Ordered response models (also known as ordinal cumulative link models) to modeling the ratings dynamics have been widely employed and analyzed in the credit rating literature (see, e.g., Afonso 2003, Bissondoyal-Bheenick et al. 2006, Afonso et al. 2009 and Erdem and Yusuf 2014). As our focus is in simulation and not in prediction, in this paper we are not interested in studying or analyzing the determinants of sovereign bond ratings (as done, e.g., in Cosset and Roy 1991 and Cantor and Packer 1996). Our focus is also not the search for the best prediction methodology (as done, e.g., in Ozturk et al. 2016). Our aim is to construct a simple (but not simplistic) model that allows us to simulate the 10-year Portuguese Government bonds ratings using as risk factor only the 10-year Portuguese Government bonds' yield.

In the gathered historical sample (monthly data from January 2003 to December 2019) we observe eight different rating levels (see Figure 9): Ba3, Ba2, Ba1, Baa3, Baa1, A3, A1 and Aa2.

Figure 9: Historical Rating Levels

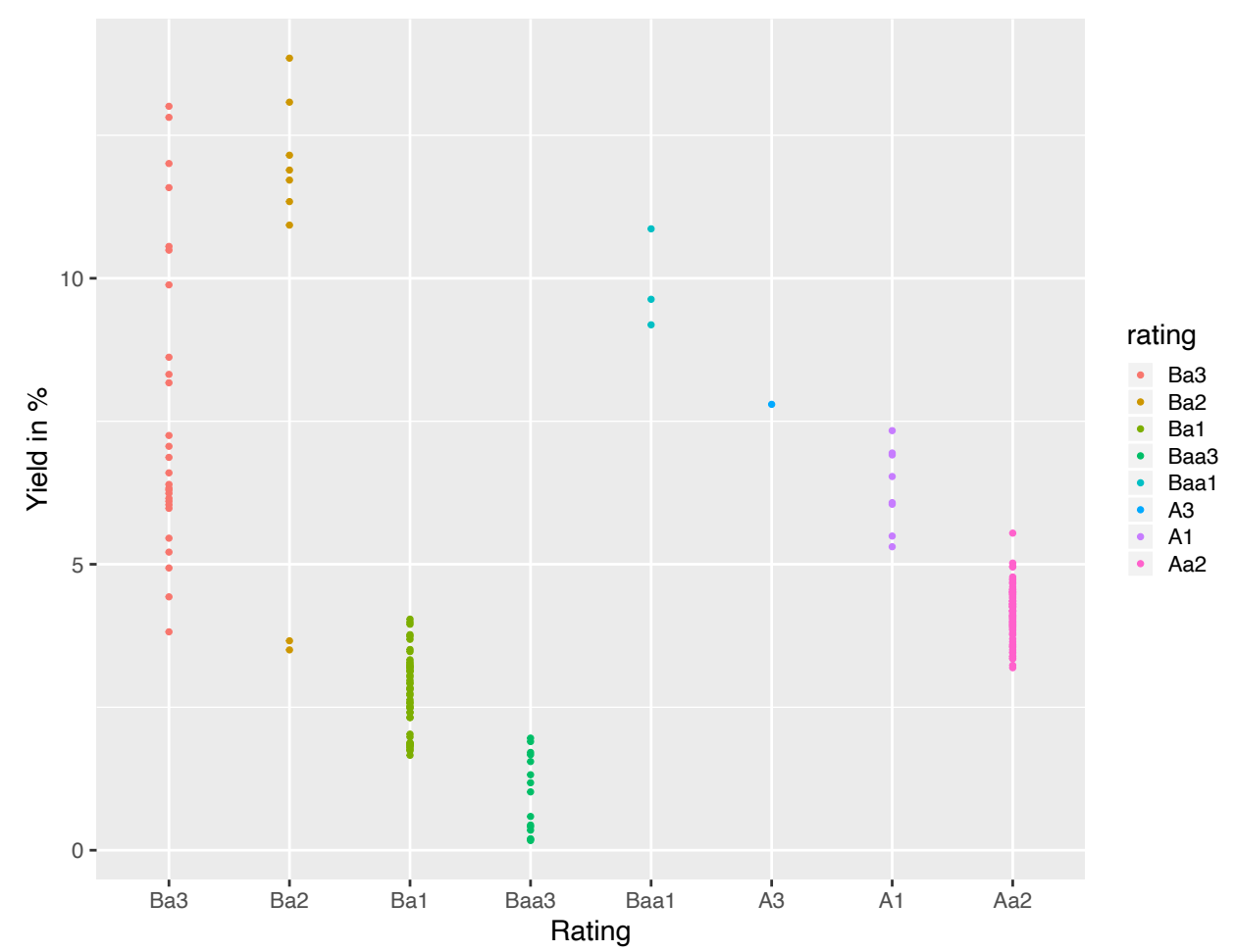

This figure reports the distribution of the rating levels as function of the 10-year Portuguese Government bonds' yield, observed during the sample time period (January 2003 to December 2019).

These rating levels can be represented in ordinal form as 


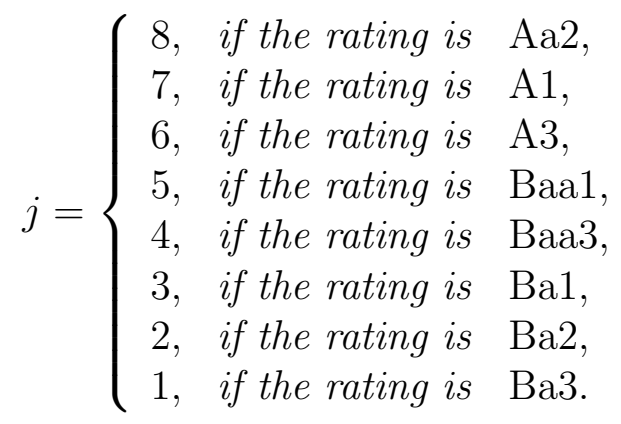

Now we can define an ordinal response model by letting $r_{t}^{*}$ be a latent variable such that

$$
r_{t}^{*}=\gamma y_{t}+\varepsilon_{t}, \quad \forall t \in\{1, \ldots, s\},
$$

where $y_{t}$ represents the bond yield and $\varepsilon_{t}$ is the stochastic disturbance term with $c d f$ given by $F(\cdot)$. Accordingly, the rating level at time $t, r_{t}$, is defined by

$$
r_{t}=j \quad \text { if } \quad c_{j-1} \leq r_{t}^{*} \leq c_{j} \quad \text { for } \quad j=1, \ldots, 8,
$$

where $-\infty \equiv c_{0}, c_{1}, \ldots, c_{7}, c_{8} \equiv+\infty$ are the strictly ordered cutoffs determined by the model. The cumulative probabilities are given by

$$
\operatorname{Prob}\left(r_{t} \leq j\right)=\operatorname{Prob}\left(r_{t}^{*} \leq c_{j}\right)=\operatorname{Prob}\left(\varepsilon_{t} \leq c_{j}-\gamma y_{t}\right)=F\left(c_{j}-\gamma y_{t}\right) .
$$

Now assuming that $\varepsilon_{t}$ follows a standard logistic distribution, we have

$$
\operatorname{Prob}\left(r_{t} \leq j\right)=\frac{e^{\left(c_{j}-\gamma y_{t}\right)}}{1+e^{\left(c_{j}-\gamma y_{t}\right)}}=\frac{1}{1+e^{-\left(c_{j}-\gamma y_{t}\right)}} .
$$

Thereby, by choosing the logistic function as the link function, it follows that

$$
\operatorname{logit}\left(\operatorname{Prob}\left(r_{t} \leq j\right)\right)=c_{j}-\gamma y_{t},
$$

where $\operatorname{logit}(\cdot)$ it is no more than the odds' logarithm, i.e.,

$$
\operatorname{logit}(p)=\log \left(\frac{p}{1-p}\right)
$$

The described model can be estimated by maximum likelihood. Typically, ordinal response models can be estimated using a regularized Newton-Raphson algorithm with step-halving (line search) and analytical expressions for the gradient and Hessian of the negative log-likelihood function (Christensen, 2018). A detailed implementation in $\mathrm{R}$ through the ordinal package can be found in Christensen (2018). We present the estimation results of the ordinal regression in Table 6 .

The results presented in Table 6 can be interpreted as follows: with a $1 \%$ increase in the bond yield the likelihood of 8 versus 1-7 (or analogously, 7 versus 1-6, or 6 versus 1-5, 
Table 6: Estimation Results of the Ordinal Regression

\begin{tabular}{|c|cc|}
\hline Coefficient & \multicolumn{2}{|c|}{ Estimate } \\
\hline $\boldsymbol{c}_{\boldsymbol{1}}$ & $-2.888^{* * *}$ & $(0.3366)$ \\
\hline $\boldsymbol{c}_{\boldsymbol{2}}$ & $-2.487^{* * *}$ & $(0.3068)$ \\
\hline $\boldsymbol{c}_{\boldsymbol{3}}$ & $-1.103^{* * *}$ & $(0.2432)$ \\
\hline $\boldsymbol{c}_{\boldsymbol{4}}$ & $-0.8158^{* * *}$ & $(0.2429)$ \\
\hline $\boldsymbol{c}_{\boldsymbol{5}}$ & $-0.7603^{* * *}$ & $(0.2434)$ \\
\hline $\boldsymbol{c}_{\boldsymbol{6}}$ & $-0.7414^{* * *}$ & $(0.2435)$ \\
\hline $\boldsymbol{c}_{\boldsymbol{7}}$ & $-0.5867^{* * *}$ & $(0.2441)$ \\
\hline $\boldsymbol{\gamma}$ & $-20.04^{* * *}$ & $(4.717)$ \\
\hline Log-Likelihood & -301.22 \\
\hline Observations & 204 \\
\hline
\end{tabular}

This table reports the estimation parameters of the ordinal response model defined by Equation (26), Equation (27), Equation (28) and Equation (29). The corresponding standard error is presented in parenthesis. *** means that the result is statistically significant at the $1 \%$ level.

or 5 versus $1-4$, or 4 versus 1-3 or 3 versus 1-2 or 2 versus 1) decreases approximately $20 \%$, this in the $\log$ odds scale.

Thus we have a methodology to simulate the funding rates, the yields and the corresponding rating levels. Proceeding accordingly, we started by simulating 100 paths (according the vector-valued CIR process defined by Equation (24)). Then we have computed the rating levels (according to the ordinal response model defined by Equation (26), Equation (27), Equation (28) and Equation (29)). In Figure 10 we report the distribution of the simulated rating levels as a function of the simulated 10-year Portuguese Government bonds' yield.

Since our interest lies in analyzing the impact of annual decisions (on annual income and annual comprehensive income), and similarly to what we did in the previous sections, we have annualized the simulated 100 paths' data. The annual simulated bond yield and funding rate correspond to an annual average. Following the correspondence defined by Equation (25), the annual simulated rating level also corresponds to an annual average (rounded value). An annualized simulated path (yield, funding and rating level) is presented in Figure 11.

Following the framework proposed in Section 3.3, we exemplify now how the bank investment manager can implement a methodology that intends to mitigate the estimation error, based in the work of Michaud and Michaud (1998), for determining optimal efficient allocations (AC or FV) to the 10-year Government bonds.

Firstly, for each one of the 100 simulated paths (yield, funding and rating level), the efficient Pareto front (solution of Problem (18)) is computed. Secondly, on each obtained 
Figure 10: Simulated Rating Levels

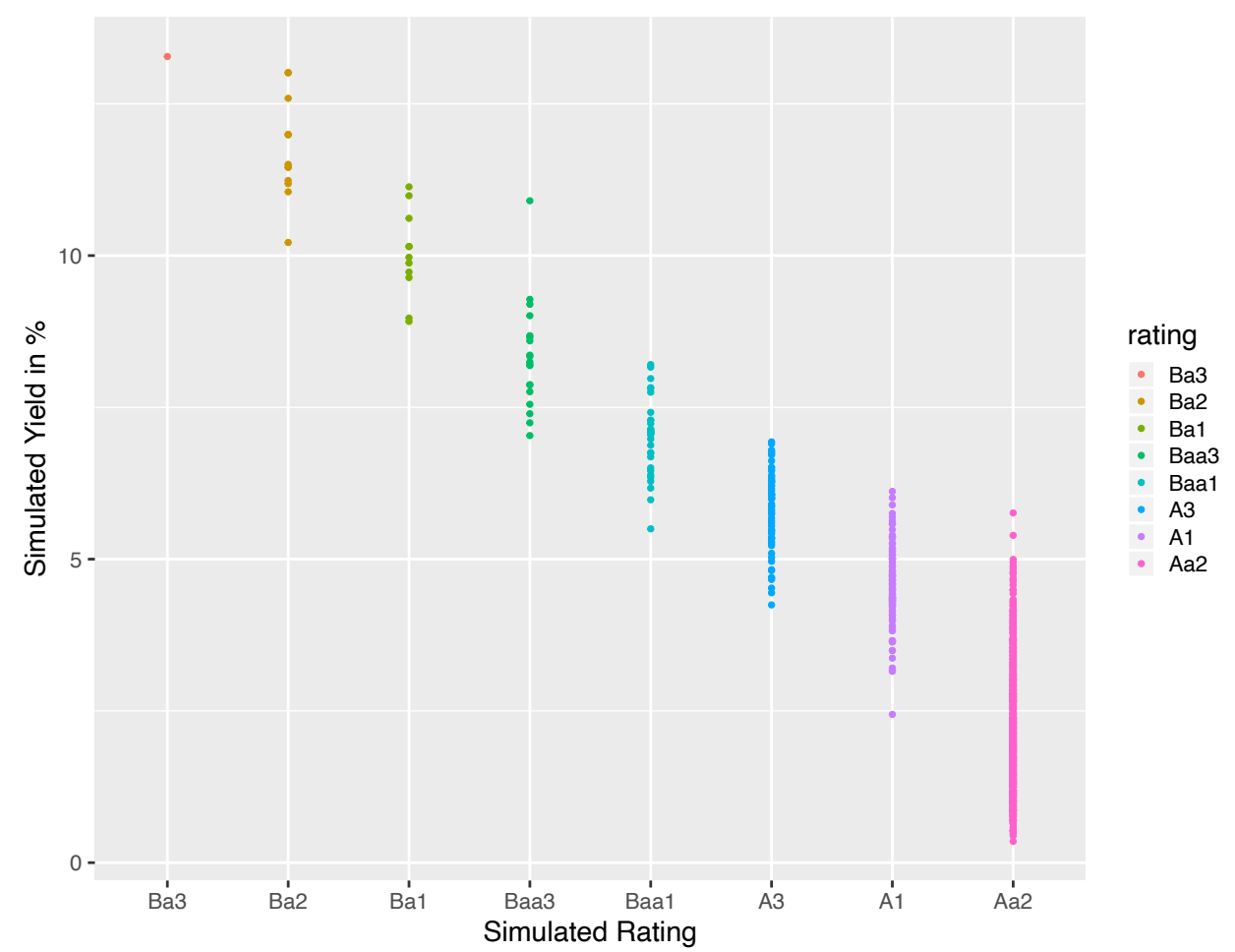

This figure reports the distribution of the simulated rating levels as a function of the simulated 10-year Portuguese Government bonds' yield. These results are reported to a simulation of 100 yields paths. 
Figure 11: Annualized Simulated Path

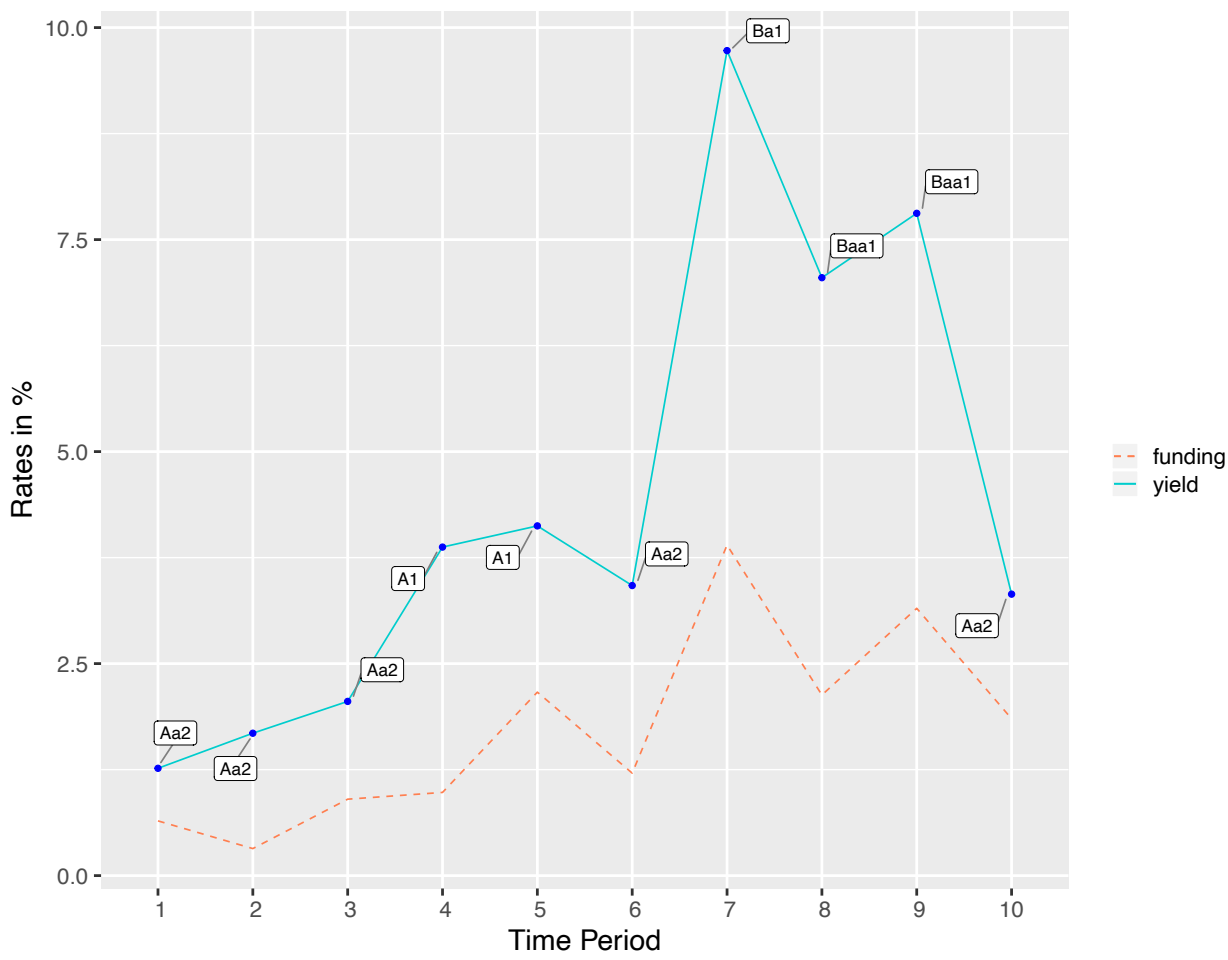

This figure reports one of the 100 simulated paths. The yields and funding rates are simulated according to the vectorvalued CIR process defined by Equation (24) and the rating levels according to the ordinal response model defined by Equation (26), Equation (27), Equation (28) and Equation (29). 
Pareto front an efficient allocation (AC and FV) is chosen according to the defined riskreturn objectives. This choice can be made based on any decision rule adopted by the bank investment manager. In this paper we decided to choose three different efficient allocations (also defined in the previous section): the allocations corresponding to the top $10 \%, 50 \%$ and $90 \%$ of risk, $w_{10}^{*(A C)}, w_{50}^{*(A C)}$ and $w_{90}^{*(A C)}$, respectively ${ }^{10}$. Thus, for each one of the 100 generated paths, we have three efficient allocations: $w_{i, 10}^{(A C)}, w_{i, 50}^{(A C)}$ and $w_{i, 90}^{(A C)}$, with $i=1, \ldots, 100$. Finally, the corresponding optimal efficient allocations are given by the average allocations, i.e., the optimal efficient allocations corresponding to the top $10 \%$, top $50 \%$ and top $90 \%$ of risk are given, respectively, by $w_{10}^{*(A C)}=\frac{1}{100} \sum_{i=1}^{100} w_{i, 10}^{(A C)}$, $w_{50}^{*(A C)}=\frac{1}{100} \sum_{i=1}^{100} w_{i, 50}^{(A C)}, w_{90}^{*(A C)}=\frac{1}{100} \sum_{i=1}^{100} w_{i, 90}^{(A C)}$. The main distributional values of these efficient allocations are reported in tables 7 to 9 .

Table 7: Efficient Allocation — Top 10\% of Risk

\begin{tabular}{|c|c|c|c|}
\hline & $\min$ value & $\max$ value & average value $\left(w_{10}^{*(A C)}\right)$ \\
\hline$w_{i, 10}^{(A C)}$ & 0.0348 & 1 & 0.6293 \\
\hline AVI & $-0.004626 \%$ & $39.43 \%$ & $10.54 \%$ \\
\hline SMV & $0.03704 \%$ & $84.746 \%$ & $12.34 \%$ \\
\hline
\end{tabular}

This table reports the main distributional values of the efficient allocation corresponding to the top $10 \%$ of risk, along the computed 100 Pareto fronts (one for each simulated path). We report the minimum, maximum and average value of the allocation to $A C$ and the risk-return metrics ( $S M V-A V I)$.

Table 8: Efficient Allocation — Top 50\% of Risk

\begin{tabular}{|c|r|r|r|}
\hline & $\boldsymbol{m i n}$ value & $\boldsymbol{m a x}$ value & average value $\left(\boldsymbol{w}_{\mathbf{5 0}}^{*(\boldsymbol{A C})}\right)$ \\
\hline $\boldsymbol{w}_{\boldsymbol{i , \mathbf { 5 0 }}(\boldsymbol{A C})}$ & 0.2086 & 1 & 0.6999 \\
\hline AVI & $-0.004626 \%$ & $37.17 \%$ & $10.23 \%$ \\
\hline SMV & $0.03704 \%$ & $57.18 \%$ & $8.326 \%$ \\
\hline
\end{tabular}

This table reports the main distributional values of the efficient allocation corresponding to the top $50 \%$ of risk, along the computed 100 Pareto fronts (one for each simulated path). We report the minimum, maximum and average value of the allocation to $A C$ and the risk-return metrics (SMV-AVI).

In Table 7 we report the results for the efficient allocation corresponding to the top $10 \%$ of risk, i.e., the efficient allocation, corresponding to the top $10 \%$ of the SMV, chosen on each of the 100 Pareto fronts (one for each simulated path). We observe that the minimum allocation to $\mathrm{AC}$ is equal to 0.0348 (which means that the maximum allocation to $\mathrm{FV}$ is equal to 0.9652 ) and the maximum allocation to $\mathrm{AC}$ is equal to 1 (the minimum allocation to $\mathrm{FV}$ is equal to 0 ). We also report the minimum values of $-0.004626 \% / 0.03704 \%$ in the

\footnotetext{
${ }^{10}$ Note that an efficient allocation $(\mathrm{AC}$ and $\mathrm{FV})$ is completely determined solely by the proportion of the investment that is allocated at AC.
} 
Table 9: Efficient Allocation — Top 90\% of Risk

\begin{tabular}{|c|r|r|r|}
\hline & $\boldsymbol{m i n}$ value & $\boldsymbol{m a x}$ value & average value $\left(\boldsymbol{w}_{\mathbf{9 0}}^{*(\boldsymbol{A C})}\right)$ \\
\hline $\boldsymbol{w}_{\boldsymbol{i}, \mathbf{9 0}}^{(\boldsymbol{A C})}$ & 0.5450 & 1 & 0.8425 \\
\hline AVI & $-0.004626 \%$ & $32.70 \%$ & $9.623 \%$ \\
\hline SMV & $0.03703 \%$ & $19.38 \%$ & $2.843 \%$ \\
\hline
\end{tabular}

This table reports the main distributional values of the efficient allocation corresponding to the top $90 \%$ of risk, along the computed 100 Pareto fronts (one for each simulated path). We report the minimum, maximum and average value of the allocation to $A C$ and the risk-return metrics (SMV-AVI).

AVI/SMV space. In turn, the maximum values in the AVI/SMV space are given by $39.43 \% / 84.746 \%$. The average allocation that we were looking for is equal to 0.6293 to $\mathrm{AC}(0.3707$ to $\mathrm{FV})$, which corresponds to a $10.54 \% / 12.34 \%$ value in the AVI/SMV space.

Analogously, in Table 8 and Table 9 we find the results for the efficient allocations corresponding to the top $50 \%$ and top $90 \%$ of risk, respectively. The average efficient allocation corresponding to the top $50 \%$ of risk is equal to 0.6999 to $\mathrm{AC}$ (0.3001 to $\mathrm{FV}$ ), which attains a $10.23 \% / 8.326 \%$ value in the AVI/SMV bi-dimensional space. In turn, the average efficient allocation corresponding to the top $90 \%$ of risk is equal to 0.8425 to $\mathrm{AC}$ ( 0.1575 to $\mathrm{FV}$ ), which attains a $9.623 \% / 2.843 \%$ value in the AVI/SMV bi-dimensional space.

In the remainder of this section we provide some insight about the out-of-sample performance of the efficient allocations according the bi-objective model (see Problem (18)). Thus, we use each of the 100 simulated paths as an out-of-sample path. Given the insample (2003-2019 is the in-sample time window) efficient allocations computed in the previous section $\left(w_{10}=[0.0441,0.9559]^{\top}, w_{50}=[0.2667,0.7333]^{\top}\right.$ and $\left.w_{90}[0.7062,0.2938]^{\top}\right)$, we assess the performance of these efficient allocations in each of the out-of-sample paths. It is interesting to contrast these results with other three different allocations: the allocation where the bank investment manager decides to allocate the investment totally to $\mathrm{AC}\left(w_{A C}=[1,0]^{\top}\right)$, totally to $\mathrm{FV}\left(w_{F V}=[0,1]^{\top}\right)$ and $50 \% / 50 \%$ of the investment distributed equally between $\mathrm{AC}$ and $\mathrm{FV}\left(w_{E W}=[0.5,0.5]^{\top}\right)$. The results are presented in Table 10.

Based on the results presented in Table 10, the efficient allocations computed according to the suggested model (solutions of Problem (18)) seem to be robust in terms of outof-sample performance. In fact, the considered in-sample efficient allocations are very consistent in both of the two objectives (AVI and SMV): note that $w_{10}, w_{50}$ and $w_{90}$ represent the ex-ante allocations corresponding to the top $10 \%, 50 \%$ and $90 \%$ of the risk, respectively (see Figure 7 ) and thereby $w_{10}$ leads to the ex-ante highest values of AVI and $\mathrm{SMV}$, followed by the $w_{50}$ allocation and finally the $w_{90}$ allocation; this pattern remains untouchable ex-post (see Table 10). Moreover, the $w_{10}$ and $w_{50}$ allocations outperform the $w_{A C}$ and $w_{E W}$ allocations in terms of ex-post average annual income (for the 10year out-of-sample period). This result is even more noteworthy taking into account 
Table 10: Out-of-Sample Performance

\begin{tabular}{|c|c|c|c|c|c|c|}
\hline \multirow{2}{*}{ Allocation Type } & \multicolumn{3}{|c|}{ AVI } & \multicolumn{3}{|c|}{ SMV } \\
\hline & $\min$ & $\max$ & average & $\min$ & $\max$ & average \\
\hline$w_{10}$ & $-0.004626 \%$ & $39.33 \%$ & $10.52 \%$ & $1.383 \%$ & $83.34 \%$ & $22.35 \%$ \\
\hline$w_{50}$ & $-0.004626 \%$ & $36.58 \%$ & $10.15 \%$ & $0.903 \%$ & $50.07 \%$ & $13.54 \%$ \\
\hline$w_{90}$ & $-0.004626 \%$ & $31.15 \%$ & $9.43 \%$ & $0.2426 \%$ & $9.257 \%$ & $2.735 \%$ \\
\hline$w_{A C}$ & $-0.004626 \%$ & $29.26 \%$ & $8.950 \%$ & $0.03703 \%$ & $1.741 \%$ & $0.3098 \%$ \\
\hline$w_{F V}$ & $-0.004626 \%$ & $39.88 \%$ & $10.59 \%$ & $1.495 \%$ & $90.93 \%$ & $24.36 \%$ \\
\hline$w_{E W}$ & $-0.004626 \%$ & $33.70 \%$ & $9.770 \%$ & $0.5449 \%$ & $24.29 \%$ & $6.722 \%$ \\
\hline
\end{tabular}

This table reports the performance, on the 100 simulated paths (corresponding to a 10-year out-of-sample period), of six different allocations: three in-sample efficient allocations $\left(w_{10}, w_{50}\right.$ and $\left.w_{90}\right)$ computed on the Pareto front solution of Problem (18), the allocation where the bank investment manager decides to allocate the investment $100 \%$ to $A C$ ( $w_{A C}$ ), $100 \%$ to $F V\left(w_{F V}\right)$ and $50 \% / 50 \%$ of the investment distributed equally between $A C$ and $F V\left(w_{E W}\right)$.

two aspects: 1) it is achieved without using any explicit methodology to deal with the parameter estimation error (as the one presented in the beginning of this section); 2) it is well known that an equally weighted allocation (here represented by the $w_{E W}$ allocation) is a hard to beat (in terms of out-of-sample performance) benchmark (for more details see the provocative paper of DeMiguel et al. 2009) and even if we consider an ex-post return/risk type measure (in this case AVI/SMV) the $w_{90}$ allocation outperforms the equally weighted allocation.

From the results presented in Table 10 it also stands out that the best ex-post performance in terms of average annual income (10.59\%) is attained by the case where the bank investment manager decides to allocate the investment totally to $\mathrm{FV}\left(w_{F V}\right)$. Nevertheless, this allocation also corresponds to the highest ex-post risk (the annual semivariance of the comprehensive income equals $24.36 \%$ ).

\section{Conclusions and Future Research}

IFRS 9 intends to harmonize accounting with risk management. From the perspective of a banking investment portfolio construction this is not an easy task, due to the inherent complexities. The bank investment manager faces the critical decision on the allocation of securities to fair value and amortized cost. We have addressed this important issue.

Since IFRS 9 does not give an explicit definition for the impairment model, in this paper we have suggested a banking impairment model in order to compute a bonds' expected credit loss. We assume that the marginal probability of default is given by a Poisson process. From the suggested impairment model results an expected credit loss that increases with the loss given default, as with the bond's maturity. We define what a significant increase in credit risk consists of: we consider the existence of a significant 
increase in credit risk if a bond has a rating level classified as "speculative grade" or if a bond has had a downgrade of at least 3 notches since origination.

A backtest on the 10-year Portuguese Government bonds was performed, for the time period between 2003 and 2019. The backtest was constructed using only three inputs: yields, funding rates and the corresponding rating levels. The results suggest that the higher the proportion of the investment allocated to fair value, the higher the variability of the annual income and the annual comprehensive income. Moreover, for the full sample period (2003-2019) if the bank investment manager decides to allocate the investment totally to fair value she/he obtains a higher value of annual average income and annual average comprehensive income than if she/he decides to allocate the investment totally to amortized cost. Nevertheless, we have shown that these results are sensitive to the choice of the threshold from which the bank investment decides to realize gains at fair value. We also have shown that these results rely on the investment time horizon which in turn can affect the bank investment manager decisions.

Based on risk-return objectives, a bi-objective optimization model was proposed in order to allow the bank investment manager to directly find efficient allocations, i.e., which proportion of the investment should be allocated to amortized cost and which proportion should be allocated to fair value. As a return measure we have defined the average annual income. In turn, as a risk measure we have defined the semivariance of the annual comprehensive income. Our proposed model generates a Pareto front. The solution of the defined non-smooth bi-objective problem, using the data related to the 10year Portuguese Government bonds for the time period from January 2003 to December 2019, was computed by means of a derivative-free algorithm based on direct multisearch. Given the experienced significant downgrades, as a result of the 2011-2014 financial crisis, the Portuguese Bond yields constitutes a very unique data set.

Simple optimization, in uncertain environments, has often proven inefficient and nonoptimal. This is due to estimation error. Thereby, we have suggested and implemented a methodology to mitigate the bi-objective optimization model estimation error. Based on the resampling methodology proposed in Michaud and Michaud (1998), we suggested an idealization of different possible future paths that can be used to compute different Pareto fronts. The optimal solution corresponds to the average efficient allocations found in each of the Pareto fronts. As inputs of the bi-objective model we have the yield, funding and rating levels, so we needed to simulate these variables. The yields and funding rates were simulated by a correlated vector-valued Cox-Ingersoll-Ross process. In turn, the rating levels were simulated using an ordinal response model. We have exemplified this approach for a 10-year period.

Finally, we have also used the simulated paths to perform an out-of-sample analysis. The results suggest that the efficient allocations given by the proposed approach are robust and very competitive in terms of the both defined optimization objectives (the average annual income and the semivariance of the annual comprehensive income).

Overall, the performed quantitative analysis seems to suggest that, for the long run, the higher the proportion of the investment allocated to fair value the higher the average annual income achieved but also the higher the semivariance of the annual comprehensive 
income. In this paper we have looked to the bank investment portfolio in terms of recent accounting rules, namely under the IFRS 9 framework. We could observe the several complexities that arise when we try to develop quantitative analyses that incorporate accounting rules. However, we are convinced that the bank investment manager needs to have this type of analysis at her/his disposal, in order to be able to make more informed decisions. Therefore, as future work we want to extend this analysis to other asset classes and to the incorporation of recent regulatory rules inherent to the Basel III framework.

\section{References}

Afonso, A. (2003). Understanding the determinants of sovereign debt ratings: Evidence for the two leading agencies. Journal of Economics and Finance, 27(1):56-74.

Afonso, A., Gomes, P., and Rother, P. (2009). Ordered response models for sovereign debt ratings. Applied Economics Letters, 16(8):769-773.

Arfken, G. B. and Weber, H. J. (2012). Mathematical Methods for Physicists: A Comprehensive Guide. Academic Press, 7th edition.

Bawa, V. S. (1975). Optimal rules for ordering uncertain prospects. Journal of Financial Economics, 2(1):95-121.

BDO (2017). IFRS 9 explained - the new expected credit loss model. https://www.bdo.co.uk/.

BDO (2018). Assessing for significant increases in credit risk under IFRS 9. https://www.bdo.co.uk/.

Bissondoyal-Bheenick, E., Brooks, R., and Yip, A. Y. N. (2006). Determinants of sovereign ratings: A comparison of case-based reasoning and ordered probit approaches. Global Finance Journal, 17(1):136-154.

Broyden, C. G. (1970). The convergence of a class of double-rank minimization algorithms. Journal of the Institute of Mathematics and its Applications, 6:76-90.

Cantor, R. and Packer, F. (1996). Determinants and impact of sovereign credit ratings. Economic Policy Review, 2(2):37-53.

Chopra, V. K. and Ziemba, W. T. (1993). The effect of errors in means, variances, and covariances on optimal portfolio choice. The Journal of Portfolio Management, 19(2):6-11.

Chou, C.-S. and Lin, H.-J. (2006). Some properties of CIR processes. Stochastic Analysis and Applications, 24(4):901-912. 
Christensen, R. H. B. (2018). Cumulative link models for ordinal regression with the $r$ package ordinal. Technical report, Technical University of Denmanrk.

Cosset, J. C. and Roy, J. (1991). The determinants of country risk ratings. Journal of International Business Studies, 22(1):135-142.

Cox, J. C., Ingersoll, J. E., and Ross, S. A. (1985). A theory of the term structure of interest rates. Econometrica, 53(2):385-407.

Custódio, A. L., Madeira, J. F. A., Vaz, A. I. F., and Vicente, L. N. (2011). Direct multisearch for multiobjective optimization. SIAM Journal on Optimization, 21(3):11091140.

Deb, K., Pratap, A., Agarwal, S., and Meyarivan, T. (2002). A fast and elitist multiobjective genetic algorithm: NSGA-II. IEEE Transactions on Evolutionary Computation, 6(2):182-197.

Deelstra, G. and Delbaen, F. (1998). Convergence of discretized stochastic (interest rate) processes with stochastic drift term. Applied Stochastic Models and Data Analysis, $14(1): 77-84$.

DeMiguel, V., Garlappi, L., and Uppal, R. (2009). Optimal versus naive diversification: How inefficient is the $1 / \mathrm{n}$ portfolio strategy? The Review of Financial Studies, 22(5):1915-1953.

Diamond, D. W. and Rajan, R. G. (2000). A theory of bank capital. The Journal of Finance, 55(6):2431-2465.

Erdem, O. and Yusuf, V. (2014). Understanding the sovereign credit ratings of emerging markets. Emerging Markets Review, 20(C):42-57.

Ernst \& Young (2017). EY IFRS 9 Impairment Banking Survey. https://www.ey.com/.

Estrada, J. (2006). Dowside risk in practice. Journal of Applied Corporate Finance, 18(1):117-125.

Estrada, J. (2008). Mean-semivariance optimization: A heuristic approach. Journal of Applied Finance, 18(1):57-72.

European Comission (2011). The Economic Adjustment Programme for Portugal. https://ec.europa.eu/. Occasional Papers.

Feller, W. (1951). Two singular diffusion problems. Annals of Mathematics, 54(1):173182.

Fishburn, P. C. (1977). Mean-risk analysis with risk associated with below-target returns. The American Economic Review, 67(2):116-126. 
Fletcher, R. (1970). A new approach to variable metric algorithms. The Computer Journal, 13(3):317-322.

Gennaioli, N., Martin, A., and Rossi, S. (2018). Banks, government bonds, and default: What do the data say? Journal of Monetary Economics, 98:98-113.

Gigerenzer, G. (2015). Simply Rational: Decision Making In The Real World. Oxford Series in Evolution and Cognition. Oxford University Press.

Goldfarb, D. (1970). A family of variable-metric updates derived by variational means. Mathematics of Computation, 24(109):23-26.

Halaj, G. (2013). Optimal asset struture of a bank - bank reactions to stressful market conditions. Working Paper Series 1533, European Central Bank.

Higham, D. and Mao, X. (2005). Convergence of Monte Carlo simulations involving the mean-reverting square root process. Journal of Computational Finance, 8(3):35-61.

Horngren, C. T., Elliot, J. A., and Sundem, G. L. (1998). Introduction To Financial Accounting. Pearson Education, 7th edition.

IFRS Foundation ${ }^{\circledR}$ (2017). IFRS Standard 9, Financial Instruments. https://www.ifrs.org/.

Jarrow, R. A. (2012). Problems with using CDS to infer default probabilities. The Journal of Fixed Income, 21(4):6-12.

Kalman, J. C. and Hammer, F. S. (1967). Linear programming and optimal bank asset management decisions. The Journal of Finance, 22(2):147-165.

Kladivko, K. (2007). Maximum likelihood estimation of the Cox-Ingersoll-Ross process: The MATLAB implementation. Technical report, University of Economics Prague.

Koehn, M. and Santomero, A. M. (1980). Regulation of bank capital and portfolio risk. The Journal of Finance, 35(5):1235-1244.

KPMG (2016). Guide to annual financial statements: IFRS 9 - Illustrative disclosures for banks. https://home.kpmg.com/.

KPMG (2017). Demystifying expected credit loss. https://home.kpmg.com/.

Kusy, M. I. and Ziemba, W. T. (1986). A bank asset and liability management model. Operations Research, 34(3):356-376.

Markowitz, H. M. (1952). Portfolio selection. The Journal of Finance, 7(1):77-91.

Markowitz, H. M. (1959). Portfolio Selection: Efficient Diversification of Investments. Cowles Commission for Research in Economics: Monographs. Yale University Press. 
Mckelvey, R. and Zavoina, W. (1975). A statistical model for the analysis of ordered level dependent variables. Journal of Mathematical Sociology, 4(1):103-120.

Michaud, R. O. (1989). The Markowitz optimization enigma: Is "optimized" optimal? Financial Analysts Journal, 45(1):31-42.

Michaud, R. O. and Michaud, R. O. (1998). Efficient Asset Management: A practical Guide to Stock Portfolio Optimization and Asset Allocation. Oxford University Press.

Moody's Investors Service (2019). Sovereign default and recovery rates, 1983-2018. https://www.moodys.com/Pages/Sovereign-Default-Research.aspx.

Nawrocki, D. N. (1999). A brief history of downside risk measures. The Journal of Investing, 8(3):9-25.

Ozturk, H., Namli, E., and Erdal, H. I. (2016). Modelling sovereign credit ratings: The accuracy of models in a heterogeneous sample. Economic Modelling, 54(2016):469-478.

PWC (2017). In depth - IFRS 9 impairment: significant increase in credit risk. https://www.pwc.com/.

Roy, A. D. (1952). Safety first and the holding of assets. Econometrica, 20(3):431-449.

Satchell, S. (2010). Optimizing Optimization: The Next Generation of Optimization Applications and Theory. Quantitative Finance. Academic Press.

Schmaltz, C., Pokutta, S., Heidorn, T., and Andrae, S. (2014). How to make regulators and shareholders happy under Basel III. Journal of Banking \&G Finance, 46(2014):311325 .

Shanno, D. F. (1970). Conditioning of Quasi-Newton methods for function minimization. Mathematics of Computation, 24(111):647-656.

Volarević, H. and Varović, M. (2018). Internal model for IFRS 9 - Expected credit losses calculation. Ekonomski Pregled, 69(3):269-297.

Weygandt, J. J., Kimmel, P. D., and Kieso, D. E. (2012). Financial Accounting, IFRS Edition. Wiley Textbooks, 2nd edition. 